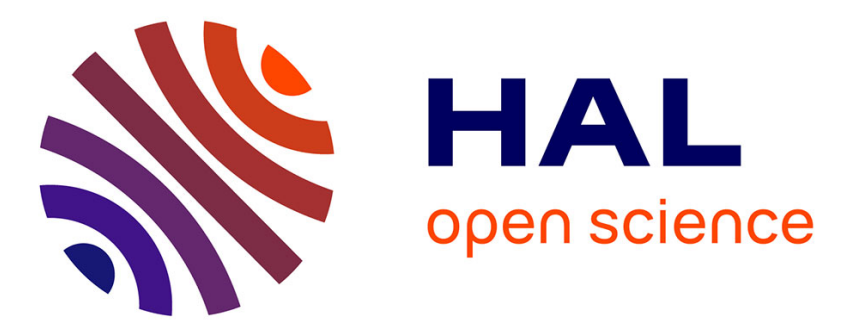

\title{
Maritime and dust aerosol retrieval from polarized and multispectral active and passive sensors
}

F. Waquet, J.-F. Léon, P. Goloub, Jacques Pelon, D. Tanré, J.-L. Deuzé

\section{To cite this version:}

F. Waquet, J.-F. Léon, P. Goloub, Jacques Pelon, D. Tanré, et al.. Maritime and dust aerosol retrieval from polarized and multispectral active and passive sensors. Journal of Geophysical Research: Atmospheres, 2005, 110 (D10), pp.D10S10. 10.1029/2004JD004839 . hal-00077967

\section{HAL Id: hal-00077967 https://hal.science/hal-00077967}

Submitted on 31 Jan 2016

HAL is a multi-disciplinary open access archive for the deposit and dissemination of scientific research documents, whether they are published or not. The documents may come from teaching and research institutions in France or abroad, or from public or private research centers.
L'archive ouverte pluridisciplinaire HAL, est destinée au dépôt et à la diffusion de documents scientifiques de niveau recherche, publiés ou non, émanant des établissements d'enseignement et de recherche français ou étrangers, des laboratoires publics ou privés. 


\title{
Maritime and dust aerosol retrieval from polarized and multispectral active and passive sensors
}

\author{
F. Waquet, J.-F. Léon, and P. Goloub \\ Laboratoire d'Optique Atmosphérique, Centre National de la Recherche Scientifique, Université de Lille 1, Lille, France
}

J. Pelon

Service d'Aéronomie, Centre National de la Recherche Scientifique, Université Pierre et Marie Curie, Paris, France

D. Tanré and J.-L. Deuzé

Laboratoire d'Optique Atmosphérique, Centre National de la Recherche Scientifique, Université de Lille 1, Lille, France

Received 31 March 2004; revised 21 October 2004; accepted 17 January 2005; published 26 March 2005.

[1] The two-dimensional structure and the optical properties of Saharan dust and maritime aerosols have been investigated over the Mediterranean Sea during October 2001 using airborne and satellite observations. A new airborne downward looking multispectral $(490-2200 \mathrm{~nm})$ micropolarimeter (MICROPOL) is used to derive the aerosol optical thickness and effective radius. We present two case studies corresponding to the observations performed during a mineral dust transport from the Sahara to Europe and to an undisturbed marine boundary layer. The dust plume is associated with aerosol optical thickness above 0.2 (at $865 \mathrm{~nm}$ ), whereas relatively low loading conditions are observed in the maritime case (down to 0.1). The MICROPOL-derived aerosol optical thickness is in an excellent agreement with coincident Moderate Resolution Imaging Spectroradiometer (MODIS) retrievals for both days. The effective radius retrieved by MICROPOL is also in a good agreement with the one from MODIS in the dust case. In the pure maritime case, this parameter is significantly underestimated by MICROPOL compared to MODIS retrieval. The vertical distribution of aerosol optical parameters is derived from combined two-wavelength backscattering airborne lidar observations and MICROPOL passive measurements. As expected in the case of a long-range transport, the aerosol effective radius within the dust layer is rather constant as a function of the altitude. A surprising low lidar depolarization factor of about $4 \%$ is retrieved within the dust plume, suggesting a major contribution of spherical particles. No significant depolarization has been observed in the marine boundary layer. For the given geometry of observation the retrieved aerosol models, which are based on the Mie theory, reproduce the MICROPOL polarized measurements within $5-8 \%$ in the dust and maritime case. The use of a nonspherical model increases by a factor of 2 the residual fitting error in polarization in the case of the dust observation. This result is confirmed by the lidar depolarization ratio and indicates that a large part of particles in the dust plume are spherical.

Citation: Waquet, F., J.-F. Léon, P. Goloub, J. Pelon, D. Tanré, and J.-L. Deuzé (2005), Maritime and dust aerosol retrieval from polarized and multispectral active and passive sensors, J. Geophys. Res., 110, D10S10, doi:10.1029/2004JD004839.

\section{Introduction}

[2] Many difficulties in assessing the climatic effect of aerosols arise because of the great spatial and temporal variability of their concentration and physical and chemical properties. Mineral dust and maritime aerosols represent the largest contribution of natural aerosols to the total atmospheric burden. Dust and sea-salt concentration in the atmosphere depend on the meteorological conditions and

Copyright 2005 by the American Geophysical Union. 0148-0227/05/2004JD004839 thus will be directly affected by climate change. In turn, natural aerosols have an impact on the radiative budget and the climate. The coarse fraction of maritime aerosols results from bursting of sea foam in windy conditions [Blanchard and Woodcock, 1980], while mineral dust results from the wind erosion of arid and semiarid areas. The properties of mineral dust depend on source locations and physical and chemical processes occurring during the transport. The presence of dust in the atmosphere is generally due to sporadic updraft of high load of material leading to strong optical thickness, whereas an important characteristic of the oceanic aerosol is the substantially lower aerosol loading. In 
the Mediterranean atmosphere, high optical thickness with a low spectral dependency are usually characteristic of a Saharan dust event [Hamonou et al., 1999; Léon et al., 1999].

[3] Many efforts have been devoted to better characterize the physical and optical aerosol properties in the frame of the development of network of ground-based instruments and Earth's observation satellite missions. The large range of spectral and angular observations provided by the ground-based Sun photometers of the Aerosol Robotic Network (AERONET) [Holben et al., 1998] are used to derive detailed aerosol properties in key locations. Satellite remote sensing offers a global and quasi-continuous monitoring of the aerosol properties [Kaufman et al., 2002]. The new generation of satellite sensors provides enhanced capacities for aerosol monitoring, like the Moderate Imaging Spectroradiometer (MODIS) and Polarization and Directionality of Earth's Reflectances (POLDER) [Deschamps et al., 1994]). The MODIS [Salomonson et al., 1989] is aboard Terra and Aqua platforms and has a wide spectral capacity ranging from the visible (VIS) to the shortwave infrared (SWIR). The observations performed in the SWIR are important to retrieve the contribution of the coarse mode of particles to the total aerosol optical thickness. The aerosol retrieval algorithm [Tanré et al., 1997] uses this wide spectral range $(0.55-2.13 \mathrm{~nm})$ to derive the spectral aerosol optical thickness and aerosol effective radius over the oceans. On the basis of a different instrumental concept, the POLDER was aboard ADEOS- 1 and ADEOS-2 platforms and had the capacity to measure the total and polarized top of the atmosphere radiances in the VIS and the near-infrared (NIR). The POLDER retrieval algorithm [Deuzé et al., 2000] derives from the total and polarized radiances the aerosol optical thickness and size parameters. It further provides information on the shape of particles from the analysis of the polarized angular scattered radiance. A new prototype of the future POLDER instrument, including polarization from the UV up to $2200 \mathrm{~nm}$, is being developed at the Laboratoire d' Optique Atmosphérique. Its development is based on the results obtained with a polarimeter, a satellite type sensor called MICROPOL, developed with the support of the Centre National d'Etudes Spatiales (CNES). MICROPOL has been already used during several field experiments to test new methodologies based on spectral and polarized measurements performed from the UV to solar infrared. An algorithm over ocean, based on MODIS approach, has been developed for this instrument [Goloub et al., 2003].

[4] Passive remote sensors miss the vertical distribution of aerosols in the atmospheric column. Lidars are currently the most sophisticated optical systems giving a description on the aerosols atmospheric profiles, and several inversion techniques were proposed for the retrieval of physical particle parameters from ground-based [Müller et al., 1999a; 1999b; Sicard et al., 2002] or airborne [Flamant et al., 1998; Pelon et al., 2002] lidar observations. It has been shown that a synergy between active (lidar) and passive (radiometer) devices results in improving the retrieval of aerosol properties [Kaufman et al., 2003a; Léon et al., 2003]. It is of particular importance in the frame of the Cloud-Aerosol Lidar and Infrared Pathfinder Satellite Observation (CALIPSO) [Winker et al., 2002], which will be launched early 2005 and will be part of a constellation of satellites called the AQUA train, including MODIS and POLDER sensors. The CALIPSO lidar (CALIOP) is a frequency-doubled $\mathrm{Nd}$ :YAG laser that transmits laser light simultaneously at 532 and $1064 \mathrm{~nm}$ and includes a crosspolarization detection channel at $532 \mathrm{~nm}$. This instrument will provide high-resolution vertical profiles of aerosols and clouds. The synergy between MODIS, POLDER, and CALIPSO is then able to significantly enhance our understanding of the aerosol distribution at a global scale. Comparable synergistic approaches were developed and tested during field campaigns where airborne lidar observations acquired simultaneously with MODIS overpasses were available to be cited: the Saharan Dust Experiment (SHADE) [Léon et al., 2003; Kaufman et al., 2003a] and the Southern African Regional science Initiative (SAFARI) [Kaufman et al., 2003b].

[5] The present paper focuses on the retrieval of the properties of natural aerosols including mineral dust and maritime aerosols derived from passive (MICROPOL) and active (the elastic backscatter lidar Lidar pour l'Etude des Interactions Ae Rosols Nuages Dynamique Rayonnement et du Cycle de l'Eau (LEANDRE)) airborne instruments. To solve most of the ambiguity in deriving aerosol profile from lidar alone, we use the MICROPOL observations to constrain the inversion of the lidar signal in terms of aerosol optical thickness and effective radius. Both instruments were deployed during the Field Radiation Experiment Natural Cirrus and High Cloud (FRENCH) [Brogniez et al., 2004] experiment, which took place over the northwestern Mediterranean Sea. The description of the flights, the observations, and the technical characteristics concerning each instrument is presented in the next section. Then we present and test the capacity of the MICROPOL to derive aerosols properties over the ocean surface. The results of the MICROPOL inversion are compared to the MODIS retrievals. In the last section we apply a synergy between MICROPOL and LEANDRE to better characterize the vertical distribution of maritime and dust aerosols.

\section{Field Experiment}

[6] The main purpose of the FRENCH campaign was to acquire simultaneous active and passive aircraft observations to characterize cirrus and high-level clouds. The French research aircraft FALCON-20 (F20) participated to this campaign from 27 September to 12 October 2001. Ten flights were performed during the campaign; four of them were dedicated to aerosol characterization over the Mediterranean Sea. The characteristics of the ten flights including the time and date, the altitude, the type of surface overflown, and the type of observations are given in Table 1. The F20 was equipped with the backscatter lidar LEANDRE-1 [Pelon et al., 1990] and the POLDER airborne simulator [Deuzé et al., 1993]. The new longwave and shortwave polarimeter MICROPOL was also operated aboard the F20. Combined ground-based and satellite observations were also available. Most of the flights were performed as close as possible to the TERRA overpass. Two days, 8 and 11 October, were particularly relevant for maritime and mineral dust aerosol characterization. The airborne measurements were acquired along round-trip transects of 
Table 1. Main Characteristics of the Ten Flights Performed During the FRENCH Experiment ${ }^{\mathrm{a}}$

\begin{tabular}{cccll}
\hline Date & Start-End Time, UT & Altitude, km & Type of Surface & \\
\hline $25 / 9 / 01$ & $1410-1440$ & 11 & ocean & Observations \\
$\mathbf{2 7 / 9 / 0 1}$ & $0840-1445$ & 9 & ocean and land & several clouds just below the aircraft $(\sim 9 \mathrm{~km})$ \\
$\mathbf{2 8 / 9 / 0 1}$ & $1345-1355$ & 11 & land & cirrus $(6-12 \mathrm{~km})$ and altostratus \\
$30 / 9 / 01$ & $1255-1450$ & 12 & ocean & cirrus $(6-12 \mathrm{~km})$ and altostratus \\
$\mathbf{1 / 1 0 / 0 1}$ & $1245-1445$ & 12 & ocean & very clear condition, several low clouds and cirrus \\
$5 / 10 / 01$ & $0850-0940$ & 11.5 & ocean and land & thick cirrus and altostratus \\
$7 / 10 / 01$ & $1155-1345$ & 12 & ocean & cirrus $(8-10 \mathrm{~km})$ and altostratus \\
$\mathbf{8 / 1 0 / 0 1}$ & $1150-1340$ & $10-12$ & ocean and land & low loading condition and cloudy structures within the marine boundary layer \\
$\mathbf{1 1 / 1 0 / 0 1}$ & $1030-1230$ & 11.5 & ocean and land & dust loading condition, a thin cirrus $(\sim 11 \mathrm{~km})$ \\
$\mathbf{1 2 / 1 0 / 0 1}$ & $0820-0920$ & 9 & land & dust loading condition, northward flight over France \\
\hline
\end{tabular}

${ }^{\mathrm{a}}$ The dates in boldface correspond to flights dedicated to an aerosol study over the Mediterranean Sea.

nearly $400 \mathrm{~km}$ between the southern coast of France and Corsica Island. The two flights were performed on 8 and 11 October, respectively, began at 1150 and 1030 UT and ended at 1340 and 1300 UT.

\subsection{Instrumental Setup}

[7] The ground-based stations of Tarbes $\left(43.25^{\circ} \mathrm{N}, 0^{\circ} \mathrm{E}\right)$, Aire-sur-Adour $\left(43.7^{\circ} \mathrm{N}, 0.25^{\circ} \mathrm{E}\right)$, Toulouse $\left(43.57^{\circ} \mathrm{N}\right.$, $\left.1.37^{\circ} \mathrm{E}\right)$, and Avignon $\left(43.91^{\circ} \mathrm{N}, 4.87^{\circ} \mathrm{E}\right)$ located in the south of France, were equipped with an automatic Cimel Sun photometer of AERONET. The operational inversion algorithm [Dubovik and King, 2000] provides the spectral aerosol optical thickness, the aerosol complex refractive index, and the particle size distribution between 0.05 and $15 \mu \mathrm{m}$. An additional manual Sun photometer was set up near the seashore at $3^{\circ} 53^{\prime} \mathrm{E}-43^{\circ} 36^{\prime} \mathrm{N}$ on 11 October.

[8] Measurements of the vertical distribution of scattering layer were performed using the backscattering lidar LEANDRE-1. The laser is a Nd:Yag delivering $10 \mathrm{~ns}$ pulses of 40 and $190 \mathrm{~mJ}$ in the 532 and $1064 \mathrm{~nm}$ channels, respectively. The laser repetition rate is $12 \mathrm{~Hz}$, which leads to a $1 \mathrm{~s}$ time averaging over 12 shots, corresponding to an horizontal resolution of about $200 \mathrm{~m}$. The emitted beam has a $3 \mathrm{mrd}$ divergence (corresponding to a spot diameter of $30 \mathrm{~m}$ at the surface when the aircraft is flying at an altitude of $10 \mathrm{~km}$ ). The receiving telescope has a diameter of $30 \mathrm{~cm}$ to keep the system compact. The depolarization ratio is derived from the ratio of the cross-polarized to the parallel lidar return signal.

[9] The MICROPOL polarimeter operates in five bands centered at 490, 670, 865, 1600, and $2200 \mathrm{~nm}$. For each wavelength, there are three separate optical systems composed of a collimator, a lens, an interferential filter, a polarizer, and a detector. The angle between the direction of the three polarizers is $60^{\circ}$. This configuration is considered to be the optimal configuration to derive the angle of polarization and the linear polarized radiance. The total and polarized normalized radiances are derived using the calibration and the combination of these three simultaneous measurements [Herman et al., 1997a]. A set of total and polarized normalized radiances at the 5 wavelengths is done in no more than $7.5 \mathrm{~ms}$. In the 1600 and $2200 \mathrm{~nm}$ channels the detectors are stabilized at a temperature of $-10^{\circ} \mathrm{C}$ (InGaAs detectors). It has been shown that the effect of temperature variation on calibration is smaller than $2 \%$ at maximum. The absolute accuracy is about $2-3 \%$ for the wavelengths $490,670,865$, and $1600 \mathrm{~nm}$ and reaches $6 \%$ for the $2200 \mathrm{~nm}$ channels. The noise equivalent differential spectral luminance in total $(\mathrm{Ne} \Delta \mathrm{L})$ and polarized $(\mathrm{Ne} \Delta \mathrm{Lp})$ normalized radiance is reported in Table 2. It corresponds to the radiometric noise converted into a normalized radiance noise. This quantity is experimentally evaluated and given here for a degree of polarization close to $30 \%$, representative of the condition of the experiment. The degree of polarization is defined as the ratio of the polarized radiance to the total radiance [Deuzé et al., 1993]. We have also estimated the corresponding noise equivalent differential optical thickness $\mathrm{Ne} \Delta \tau$ at $2200 \mathrm{~nm}$ using the single scattering approximation in the most unfavorable conditions [Tanré et al., 1997]. When considering a scattering angle of $120^{\circ}, \mathrm{Ne} \Delta \tau$ is equal to $3.10^{-3}$ and $2.10^{-3}$, respectively for a maritime and mineral dust model [Shettle and Fenn, 1979].

[10] MODIS was successfully launched in December 1999 on board NASA's spacecraft Terra and began collecting data in March 2000. The instrument performs spectral measurements from 415 to $14235 \mathrm{~nm}$ in 32 spectral bands. The resolution of the subnadir pixel is from $250 \mathrm{~m} \times 250 \mathrm{~m}$ to $1 \mathrm{~km} \times 1 \mathrm{~km}$, while the aerosol parameters are retrieved at a resolution of $10 \mathrm{~km} \times 10 \mathrm{~km}$. An operational algorithm, based on a lookup table (LUT) approach, has been developed for deriving aerosol properties over open ocean surfaces. The algorithm uses six spectral channels ranging from 550 to $2130 \mathrm{~nm}$. The principle of the inversion and the description of the aerosol models are presented in the section 3.1. The main aerosol products derived from MODIS include the spectral aerosol optical thickness (AOT), the effective radius of the size distribution, and the fraction of the total aerosol optical thickness coming from the fine aerosol mode $(\eta)$. MODIS aerosol products have been validated using AERONET Sun photometer measurements [Remer et al., 2002]. The spectral AOT over ocean is retrieved within an accuracy of $0.03 \pm 0.05 \times$ AOT. The absolute accuracy on the effective radius is $\pm 0.1 \mu \mathrm{m}$. A sensitivity study has emphasized the difficulty to retrieve the parameter $\eta$ accurately, which is generally considered as an estimate with an uncertainty of \pm 0.25 [Tanré et al., 1997].

Table 2. MICROPOL Radiometric Accuracy in Total $(\mathrm{Ne} \Delta \mathrm{L})$ and Polarized $\left(\mathrm{Ne} \Delta \mathrm{L}_{\mathrm{P}}\right)$ Normalized Radiance and for the Five Bands

\begin{tabular}{cccc}
\hline Center Wavelength, nm & Maximum Radiance & $\mathrm{Ne} \Delta \mathrm{L}$ & $\mathrm{Ne} \Delta \mathrm{Lp}$ \\
\hline 490 & 0.30 & $1 \times 10^{-5}$ & $6 \times 10^{-5}$ \\
670 & 0.23 & $9.5 \times 10^{-6}$ & $8 \times 10^{-5}$ \\
865 & 0.44 & $8 \times 10^{-6}$ & $7 \times 10^{-5}$ \\
1600 & 0.94 & $1.5 \times 10^{-5}$ & $1 \times 10^{-4}$ \\
2200 & 0.62 & $4 \times 10^{-5}$ & $8 \times 10^{-5}$ \\
\hline
\end{tabular}




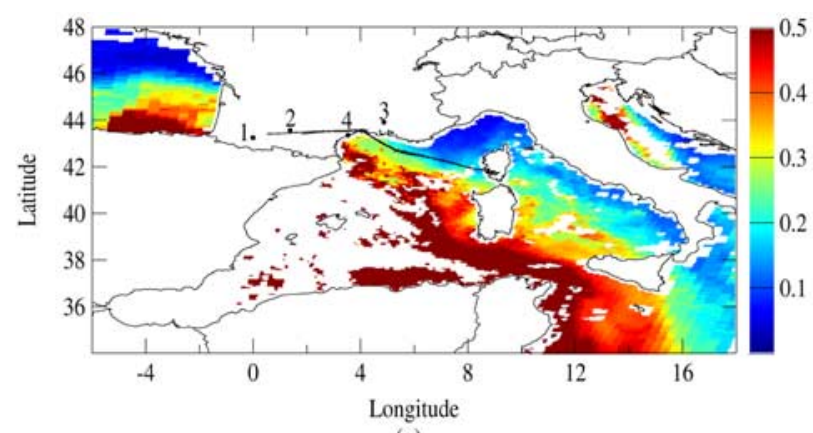

(a)

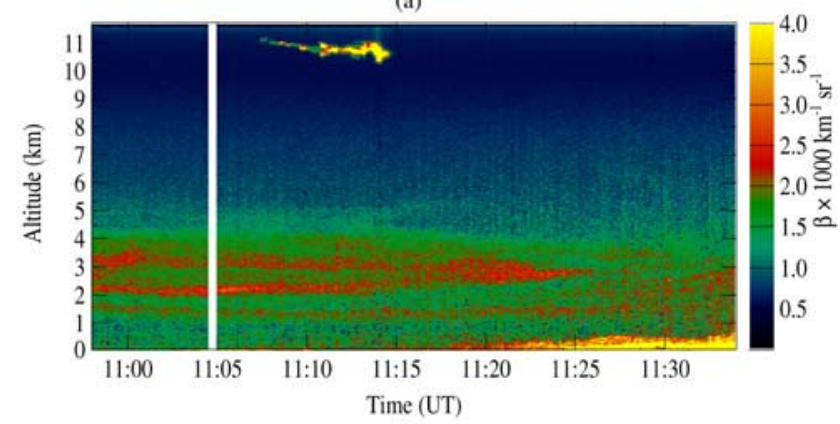

(b)

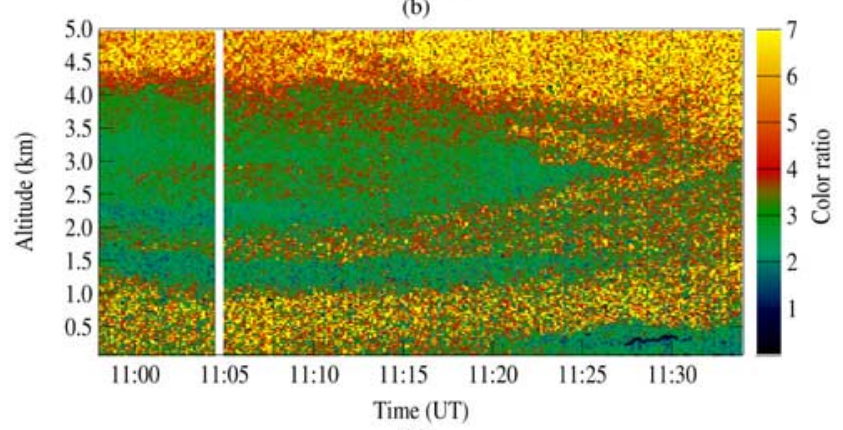

(c)

Figure 1. (a) MODIS aerosol optical thickness at $865 \mathrm{~nm}$, on 11 October. The black dots correspond to the locations of the Sun photometers of Tarbes (1), Toulouse (2), Avignon (3), and the location of an additional Sun photometer settled along the sea shore (4). (b) Lidar attenuated backscatter coefficients at $532 \mathrm{~nm}$ and (c) pseudo-color ratio computed over the 532 and $1064 \mathrm{~nm}$ lidar backscatter coefficients measured below the track of the airplane.

\subsection{Observations}

[11] Synoptic meteorological observations revealed a high-pressure system over the eastern part of France and a low-pressure system over the Canary Island, leading to a southeasterly advection of air masses from Africa potentially rich in desert particles. Figure 1a displays the aerosol optical thickness (at $865 \mathrm{~nm}$ ) derived from MODIS on 11 October. Areas where the retrieval is not possible, like cloudy sky or observations in the specular direction, are drawn in white. Continental areas are also in white. The black solid lines are the ground tracks of the F20 for the flight performed on the same day between 1100 and 1300 UTC. Acquisition time of MODIS data is about 1030 UT. The observed situation corresponds to a transport of a large dust plume, associated with AOT above 0.5 and extending from the African coast, to the northwestern part of the Mediterranean Sea. The minimum and maximum AOT observed in Toulouse and Tarbes by the Sun photometer were 0.2 and 0.5 , respectively.
The daily average Angström exponent, computed between the 670 and $865 \mathrm{~nm}$ channels [Deuzé et al., 2000], was 0.25 for Toulouse and close to 0 for Tarbes. It indicates the presence of large particles, as expected in the case of a mineral dust transport. Near the area of investigation the AOT measured by the Avignon Sun photometer was rather low, between 0.1 and 0.2, while the Angström exponent was between 1.0 and 0.1 along the day. As shown on Figure 1a, the F20 has progressively deviated from the deep plume region. The MODIS AOT sampled along the F20 aircraft tracks decreases from 0.25 near the continent to 0.15 or less near Corsica.

[12] The lidar return signal depends on the aerosol extinction and backscatter cross section as well as particle number concentration. The lidar signal is normalized and range-corrected to provide the attenuated backscatter coefficient presented in Figures $1 \mathrm{~b}$ and $2 \mathrm{~b}$. The calibration factor is derived by matching portions of the measured backscattering profile taken to arise from pure molecular scattering.
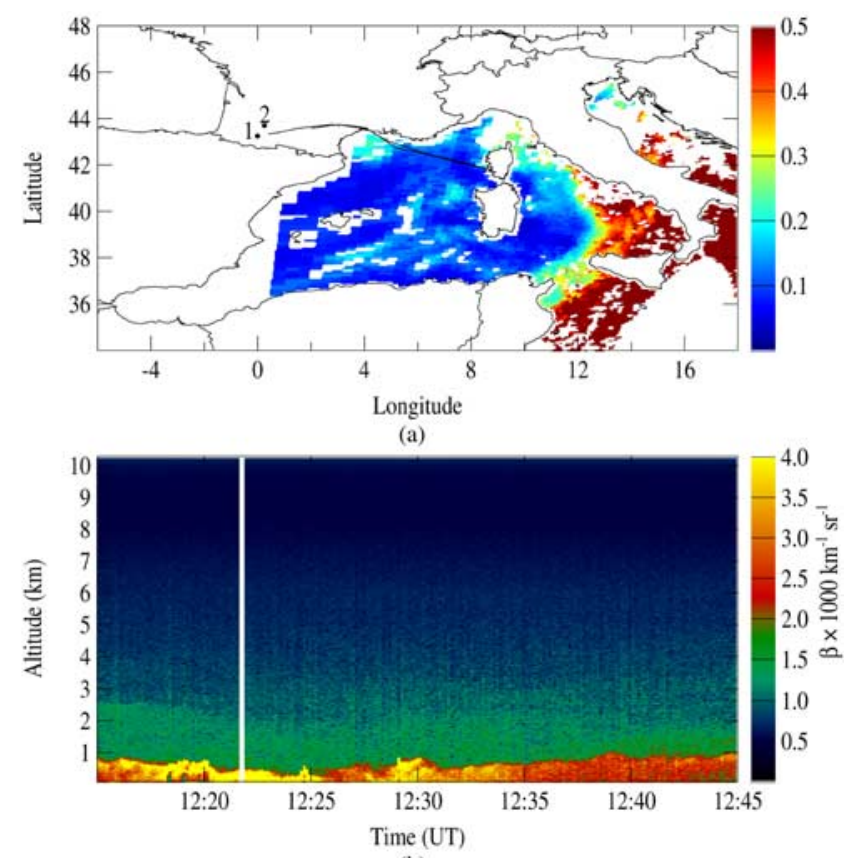

(b)

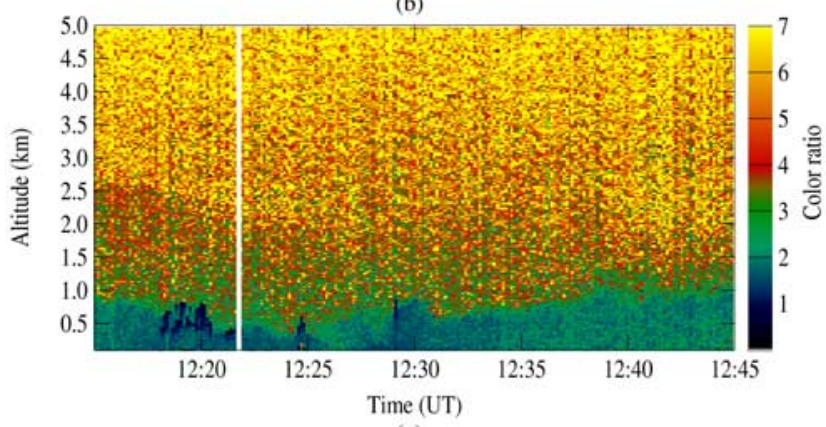

(c)

Figure 2. (a) MODIS aerosol optical thickness at $865 \mathrm{~nm}$ on 8 October. The black dots correspond to the locations of the Sun photometers of Tarbes (1) and Aire-sur-Adour (2). (b) Lidar attenuated backscatter coefficients at $532 \mathrm{~nm}$ and (c) pseudo-color ratio computed over the 532 and $1064 \mathrm{~nm}$ lidar backscatter coefficients measured below the track of the airplane. 
The pure molecular backscatter coefficient is measured in the upper part of the atmosphere just below the aircraft. The attenuated backscatter coefficient corresponds to the product of the total (molecules and aerosols) backscatter coefficient for a given altitude by the two-way transmission between the laser source and the given altitude. The attenuated lidar backscatter coefficient is used to depict the vertical structure of the aerosol. Figure $1 \mathrm{~b}$ presents the attenuated backscatter coefficient $\beta$ measured at $532 \mathrm{~nm}$ on 11 October from $1058 \mathrm{UT}\left(43.35^{\circ} \mathrm{N}, 4.35^{\circ} \mathrm{E}\right)$ to $1135 \mathrm{UT}\left(42.22^{\circ} \mathrm{N}, 7.26^{\circ} \mathrm{E}\right)$ during the transect from Corsica to the continent shown in Figure 1a. The ratio of the 532-1064 nm attenuated backscatter coefficient (hereinafter called the pseudo-color ratio (PCR), which is unitless) is indicative of the mean size of the particles. The PCR (presented in Figure 1c) decreases as a function of size particle, equal to 16 for molecules and close to 0 for the largest aerosols or droplets. A different vertical scale (from 0 to $5 \mathrm{~km}$ ) is used for the PCR to focus on the aerosol layer and the low cloud structure.

[13] The lidar cross section (Figure 1b) reveals a deep dust layer between the sea surface up to $6 \mathrm{~km}$ high. Several maxima in the backscatter coefficient are observed within the plume. The first is located at about $1.5 \mathrm{~km}$ and remains at the same altitude over the whole flight. Two additional maxima are observed between 2 and $4 \mathrm{~km}$. As the aircraft moves over the sea (corresponding to a time increase), there is only one deep plume located at $3 \mathrm{~km}$ high. Low values of the color ratio, ranging from 1.5 to 3.5 , are associated with the dust plume. An increase in the attenuated backscatter coefficient associated with a sharp decrease in the PCR is observed in the marine boundary layer at the end of the transect. This indicates the impact of the condensation of water onto the particles. The high values of backscatter coefficient observed between 1107 and 1115 UT at $11 \mathrm{~km}$ high can be associated with the occurrence of a thin cirrus cloud.

[14] The origin of the dust layer located between 2 and $4 \mathrm{~km}$ high (Figure $1 \mathrm{~b}$ ) was inferred using back trajectories from the NOAA Hybird Single-Particle Lagrangian Integrated Trajectory (HYSPLIT) model (http://www.arl.noaa. gov/ready/hysplit4.html) and using the Total Ozone Mapping Spectrometer (TOMS) absorbing aerosol index [Herman et al., 1997b] (http://toms.gsfc.nasa.gov/aerosols/ aerosols.html). The dust source was identified to be located over the center of the Sahara, northwest of the Hoggar Massif (south Algeria). This location, which receives extensive drainage from the Hoggar, is known to be an area of strong dust emission [Prospero et al., 2002]. The TOMS aerosol index suggests that the dust was uplifted on 9 October and then advected over Algeria and the Mediterranean Sea following a straight south-north axis prior to its detection on 11 October.

[15] The MODIS data acquired on 8 October at 1000 UTC are reported in Figure 2a. We can observe that the optical depth remains small, below 0.15 over the western part of the Mediterranean Sea. AOT values larger than 0.4 appear on the eastern part of the map, corresponding to an anterior dust outbreak. The daily average AOT measured at Tarbes and Aire-sur-Adour were 0.065 and 0.07 and did not vary much during the day, within \pm 0.01 . The Angström exponent was 0.5 for both Sun photometers. It indicates that the contribution of anthropogenic aerosols from the continent to the area of measurements is minimized.

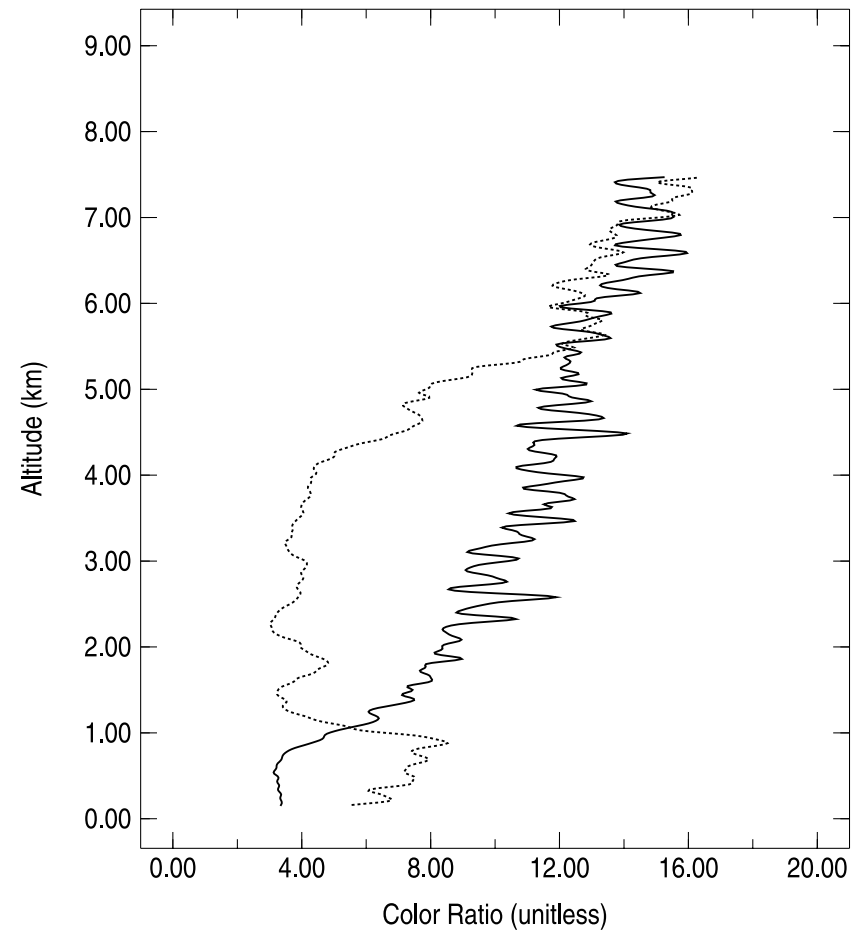

Figure 3. Vertical profiles of the pseudo-color ratio on (dashed line) 11 October and (solid line) 8 October.

[16] A deep marine boundary layer is observed to develop up to $1 \mathrm{~km}$ high over the sea surface. The backscatter coefficient in the marine boundary layer, whose height remains at about $600 \mathrm{~m}$, is much larger as small cumulus developed (around 1220 and 1230 UT). Figures $2 \mathrm{~b}$ and $2 \mathrm{c}$ give lidar observations from $1215\left(43.45^{\circ} \mathrm{N}, 4.25^{\circ} \mathrm{E}\right)$ to 1245 UT $\left(41.78^{\circ} \mathrm{N}, 8.5^{\circ} \mathrm{E}\right)$ over the same area as in Figures $1 \mathrm{~b}$ and $1 \mathrm{c}$, but for this pure maritime case. The increase in the attenuated backscatter coefficient is well correlated with the decrease in the PCR (e.g., between 1218 and 1224 UT) in the vicinity of shallow clouds embedded into the marine boundary layer. An increase in the backscatter coefficient associated with a small value of the PCR shows that a fairly significant number of aerosol particles are present above the marine boundary layer up to 3 and $4 \mathrm{~km}$ high. The average PCR profile given in Figure 3 clearly indicates the presence of coarse particles up to $6 \mathrm{~km}$ high on 11 October. The marine boundary layer is characterized by a larger value of the pseudo-color ratio than in the dust layer above. The PCR in the marine boundary layer is also higher on 11 October than on 18 October. It indicates that the dust transport occurs above the marine boundary layer and slightly affects it. The color ratio difference observed between 8 and 11 October may be due to a difference in the sea-salt concentration as the result of a difference in the sea surface wind speed (not measured). In the clean marine boundary layer the aerosol composition is basically a mix of sea salt and sulfates particles. The sulfate aerosol content depends on the type of air mass and its history and may have both a natural or anthropogenic origin. The sea particles have a natural origin and their concentration depends on the surface wind speed [Flamant et al., 1998]. The average 


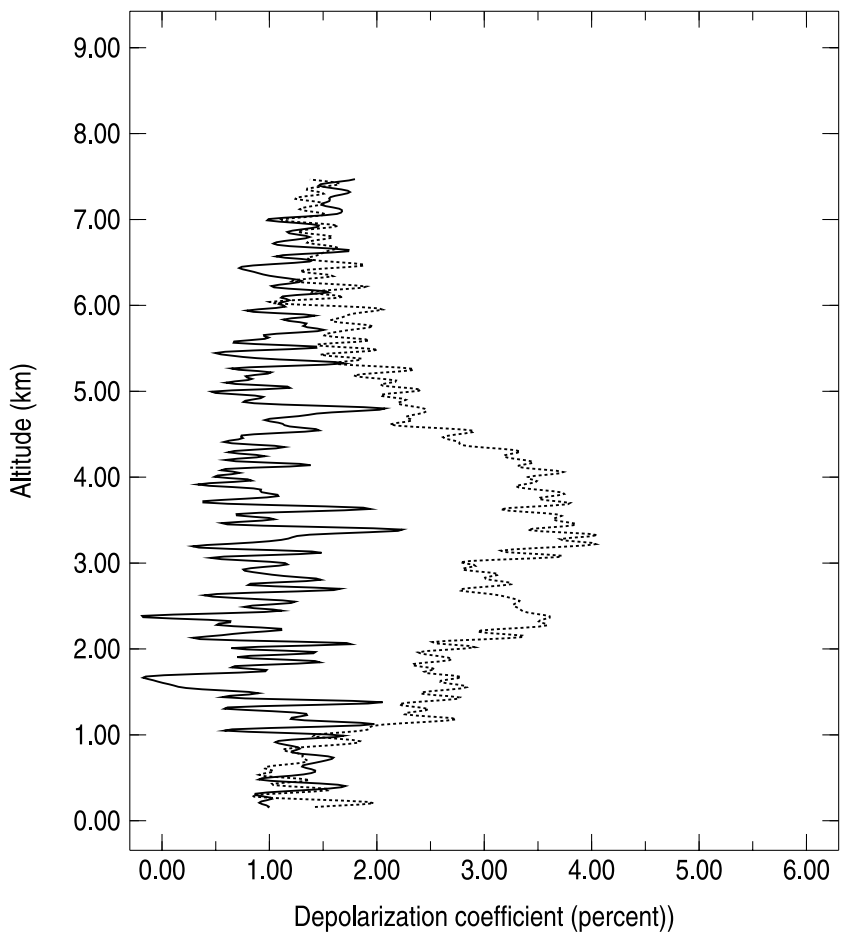

Figure 4. Depolarization coefficients on (dashed line) 11 October and (solid line) 8 October.

wind speed (NOAA Air Resources Laboratory) at the surface was $10 \mathrm{~m} \mathrm{~s}^{-1}$ and was oriented from west to east.

[17] The lidar generates short pulses of polarized light. Radiation backscattered by homogeneous spherical particles will maintain the original (parallel) polarization, whereas nonspherical particles induce some degree of polarization [Sassen and Takano, 2000]. Anisotropy in the structure of air molecules generates a small amount $(1.4 \%$ in the case of our lidar system) of depolarization. Figure 4 presents the average depolarization ratio profiles for 11 and 8 October. Although measurements are noisy, a depolarization ratio up to $4 \%$ is observed within the dust layer whereas no depolarization is observed in the marine boundary layer. It confirms that there is no dust in the marine boundary layer. In the case of the maritime air profile, no significant depolarization is observed.

\section{Methods and Results}

\subsection{MICROPOL Algorithm and Models}

[18] An operational algorithm has been developed for MICROPOL, dedicated to the retrieval of aerosol properties over dark ocean surface [Goloub et al., 2003]. The algorithm is similar to the MODIS one [Tanré et al., 1997] and has been adapted to the MICROPOL wavelengths. The MICROPOL measures the total radiance and the state of polarization of the light reflected by the atmosphere-surface system at the five given wavelengths. In the following we consider two retrieval schemes. The first one makes use of total spectral radiances, while the second one uses total and polarized radiances. Both inversions are based on a lookup table approach, where we use the successive order of multiple scattering code [Deuzé et al., 1988] for the computation of the total and polarized radiances over the ocean.
It accounts for scattering by molecules and aerosol particles as well as by foam and also accounts for Sun glint (see the Cox and Munk [1954] model). Computations are performed for several values of the atmospheric aerosol optical thickness from 0 (pure Rayleigh scattering) to 3 (turbid atmosphere). The lookup table is built for a set of solar zenith angles $\theta_{\mathrm{s}}$, viewing zenith angles $\theta_{\mathrm{v}}$, and relative azimuth $\phi$. The lookup table is generated for a set of aerosol models, which consist of four small and five large modes. We assume that the aerosol size distribution follows a bimodal size distribution composed of two lognormal modes. The single-mode lognormal distribution function is defined in equation (1) and is given for a number distribution:

$$
\frac{d N(r)}{d r}=\frac{N_{0}}{r \sigma_{m} \sqrt{2 \pi}} \exp \left[-\frac{\left[\ln \left(r / r_{m}\right)\right]^{2}}{2 \sigma_{m}^{2}}\right],
$$

where $\mathrm{N}_{0}$ is the density number $\left(\mathrm{cm}^{-2}\right), \mathrm{r}_{\mathrm{m}}$ is the mean radius of the number distribution; $\sigma_{\mathrm{m}}$ is the standard deviation of $\ln (r)$. The aerosol models are the same as in the MODIS retrieval [Tanré et al., 1997]. The parameters $\sigma_{\mathrm{m}}$, $\mathrm{r}_{\mathrm{m}}$, and the physical properties of the aerosol models are given in Table 3. The refractive index presented in Table 3 is given for each models at $865 \mathrm{~nm}$. The refractive index is slightly wavelength-dependent. The refractive index at each wavelength is given in the work of Remer et al. [2002]. The optical properties of the first nine models are computed using the Mie theory. The models numbered from 1 to 4 refer to the small particle modes with effective radii (defined as the ratio of the third to the second moment of the size distribution), ranging from 0.08 to $0.15 \mu \mathrm{m}$, while models numbered from 5 to 9 refer to the large particle mode with effective radii ranging from 0.97 to $2.36 \mu \mathrm{m}$. The mineral dust and maritime aerosol models identified here as 8 and 9 and as 5, 6, and 7 are mainly distinguished on one hand by the real part of the refractive index, respectively equal to 1.53 for mineral dust and 1.45 for maritime aerosols, and on the other hand by the values of the effective radii, ranging respectively from 1.46 to $2.36 \mu \mathrm{m}$ for the mineral dust, and from 0.97 to $1.94 \mu \mathrm{m}$ for maritime aerosols. An experimental model describing the scattering properties of large nonspherical particles [Volten et al., 2001] has been added to the nine former aerosol models. This model results from laboratory measurements of the scattering function at 675 and $440 \mathrm{~nm}$ of samples of mineral dust. We assume that the scattering properties (total and polarized) of the experi-

Table 3. Microphysical and Optical Properties of Aerosol Models $^{\mathrm{a}}$

\begin{tabular}{ccccccl}
\hline Model & $\mathrm{r}_{\mathrm{m}}$ & $\sigma_{\mathrm{m}}$ & $\mathrm{r}_{\text {eff }}$ & $\sigma_{\text {eff }}$ & $\mathrm{m}_{\mathrm{r}}-\mathrm{m}_{\mathrm{i}} \mathrm{i}$ & Comments \\
\hline 1 & 0.07 & 1.49 & 0.10 & 1.17 & $1.45-0.0035 \mathrm{i}$ & wet water soluble type \\
2 & 0.06 & 1.82 & 0.15 & 1.39 & $1.45-0.0035 \mathrm{i}$ & wet water soluble type \\
3 & 0.08 & 1.82 & 0.19 & 1.39 & $1.40-0.0020 \mathrm{i}$ & water soluble with humidity \\
4 & 0.10 & 1.82 & 0.24 & 1.39 & $1.40-0.0020 \mathrm{i}$ & water soluble with humidity \\
5 & 0.40 & 1.82 & 0.97 & 1.39 & $1.45-0.0035 \mathrm{i}$ & wet sea salt type \\
6 & 0.60 & 1.82 & 1.46 & 1.39 & $1.45-0.0035 \mathrm{i}$ & wet sea salt type \\
7 & 0.80 & 1.82 & 1.94 & 1.39 & $1.45-0.0035 \mathrm{i}$ & wet sea salt type \\
8 & 0.60 & 1.82 & 1.46 & 1.39 & $1.53-0.0010 \mathrm{i}$ & dust-like type \\
9 & 0.50 & 2.22 & 2.36 & 1.66 & $1.53-0.0010 \mathrm{i}$ & dust-like type \\
\hline
\end{tabular}

${ }^{\mathrm{a}}$ Model 10 is nonspherical. 
mental model are also valid in the middle infrared up to $2200 \mathrm{~nm}$. The phase function of the nonspherical model and the phase function of the large spherical models 5 and 9 are given in Figure 5 at a wavelength of $865 \mathrm{~nm}$. We can notice that the main feature of the nonspherical phase function is a relatively flat directional behavior in the backscattering direction compared to an increase of the phase function observed for large spherical particle.

[19] Our approach to use the LUT in the algorithm is based on the simplification suggested by Wang and Gordon [1994] that the multiple scattering radiance from two lognormal modes can be approximated by the weighted of the radiance of each individual mode for the same optical thickness. The method is exact in the single-scattering approximation. In other cases the method usually reproduces the aerosol contribution within $2-3 \%$ for aerosol optical thickness as large as 0.50 and for Sun and viewing angles as large as $80^{\circ}$ and $70^{\circ}$. Difficulties may be encountered when the aerosol is strongly absorbing; in that case, this simplification is not valid. However, this concept is quite suitable in our conditions. Then the total spectral radiance $\mathrm{L}_{\lambda}^{\mathrm{c}}$ at the instrument level is written as the sum of the small particle radiance $\mathrm{L}_{\lambda}^{\mathrm{s}}$ and the large particle radiance $L_{\lambda}^{1}$ and is computed for the same aerosol optical thickness $\delta$, molecular optical thickness, and surface contribution. The small and large particle radiances are weighted by the small mode concentration $\eta$ :

$$
L_{\lambda}^{c}\left(\delta, \mu_{s}, \mu_{v}, \phi\right)=\eta L_{\lambda}^{s}\left(\delta, \mu_{s}, \mu_{v}, \phi\right)+(1-\eta) L_{\lambda}^{l}\left(\delta, \mu_{s}, \mu_{v}, \phi\right) .
$$

First, the optical thickness is estimated from total radiance at $865 \mathrm{~nm}$ by an interpolation method for three values of the small mode concentration $(0,0.5$, and 1$)$ and for the $4 \times 6$ aerosol model combinations. Then the radiances at the other wavelengths, namely 670, 1600, and $2200 \mathrm{~nm}$, are simulated using equation (2). The residual error $\varepsilon_{R}$ is obtained following equation (3). Sensitivity tests on the MODIS algorithm have shown that $\varepsilon_{\mathrm{R}}$ is a good indicator of the quality of the retrieval [Tanré et al., 1997].

$$
\varepsilon_{R}=\sqrt{\frac{1}{4} \sum_{k=1}^{4}\left(\frac{L_{k}^{m}\left(\mu_{s}, \mu_{v}, \phi\right)-L_{k}^{c}\left(\mu_{s}, \mu_{v}, \phi\right)}{L_{k}^{m}+0.01}\right)^{2}} .
$$

$\mathrm{L}_{\mathrm{k}}^{\mathrm{m}}$ is the total normalized measured radiances for the channel $\mathrm{k}$, and $\mathrm{L}_{\mathrm{k}}^{\mathrm{c}}$ is the simulated one.

[20] The surface contribution at $490 \mathrm{~nm}$ is very uncertain when no information on the ocean color is available. As it may result in errors in the estimate of the aerosol contribution, the total radiance at $490 \mathrm{~nm}$ is not used in this retrieval scheme. The small particle concentration is then adjusted iteratively to minimize residual error for every $4 \times 6$ combination. The combination that gives the smallest $\varepsilon_{R}$ for the best selected value of $\eta$ is called "R solution" where " $R$ " stands for radiance. Then the derived solution of AOT and $\eta$ are used to compute the residual error $\varepsilon_{\mathrm{RP}}$ in the polarized channels following equation (4).

$$
\varepsilon_{R P}=\sqrt{\frac{1}{5} \sum_{k=1}^{5}\left(\frac{L p_{k}^{m}\left(\mu_{s}, \mu_{v}, \phi\right)-L p_{k}^{c}\left(\mu_{s}, \mu_{v}, \phi\right)}{L p_{k}^{m}+0.001}\right)^{2}} .
$$

Lp stands for normalized polarized radiance.

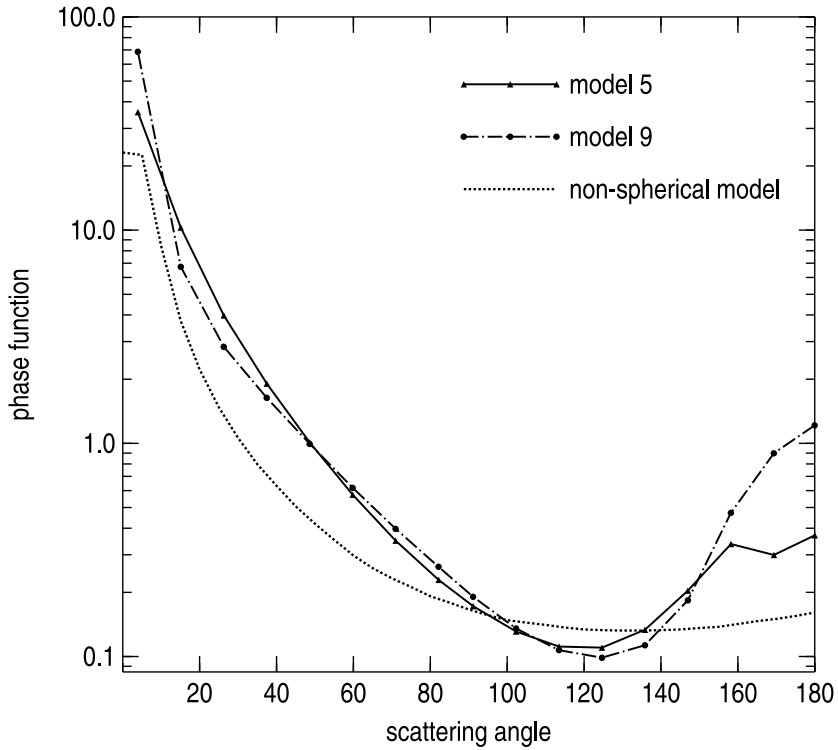

Figure 5. The scattering phase function for the nonspherical model and the MODIS large spherical model numbered 5 and 9 (see Table 3 ).

[21] The polarization of the ocean surface generated by pigment concentration at $490 \mathrm{~nm}$ can be neglected [Chami et al., 2001]. The atmospheric polarized contribution is then largely predominant at this wavelength. Then we use the polarized channel at $490 \mathrm{~nm}$ in this retrieval scheme. The single scattering contribution in polarized intensities is higher than in total intensities because it is principally low orders of scattering that contribute to polarized radiation [Leroy et al., 1997]. Since the Wang and Gordon approximation is exact for single scattering, then equation (2) is even more likely to be applicable to polarized intensities (as compared to total intensities). We reject the solutions for which the total residual error $\varepsilon_{T}=\left(\varepsilon_{R}+\varepsilon_{R P}\right) / 2$, computed for the total and polarized radiances, is larger than $5 \%$. Another solution is found by minimizing $\varepsilon_{\mathrm{T}}$. This solution is called " $\mathrm{R}+\mathrm{P}$ solution." A different set of aerosol parameters than for the "R solution" can be retrieved. We consider the " $\mathrm{R}+\mathrm{P}$ solution" only when the retrievals exhibit significant differences with the "R solution." Where the difference is as important as the accuracy associated to the retrievals (the accuracy on MODIS retrievals, given in section 2.1, is considered here), both solutions are presented and compared.

\subsection{MICROPOL Retrievals}

[22] In order to point out the spectral behavior of the optical properties of the aerosol (maritime and dust) observed during the campaign, we have selected two short transects per day. Mean reflectance and standard deviations computed over the four selected oceanic zones are reported in Tables $4 \mathrm{a}$ and $4 \mathrm{~b}$ for the total and polarized reflectances, respectively. The reflectance is defined as the ratio of the normalized radiance to the cosine of the solar zenith angle [Deuzé et al., 1993]. The selected areas correspond to two portions of the flight between 1102 and 1107 UT, and 1115 and 1120 UT on 11 October, as well as on 8 October between 1126-1229 and 1235-1240 UT. The viewing geometry is nearly the same for both days. The solar zenith 
Table 4a. Mean Reflectances Expressed in Percent and Standard Deviations for the Transects Selected on 8 October (Zones 1 and 2) and on 11 October 2001 (Zones 3 and 4)

\begin{tabular}{ccccc}
\hline Band, nm & Zone 1 & Zone 2 & Zone 3 & Zone 4 \\
\hline 670 & $1.37 \pm 0.02$ & $1.375 \pm 0.025$ & $2.46 \pm 0.05$ & $2.12 \pm 0.04$ \\
865 & $0.69 \pm 0.02$ & $0.72 \pm 0.025$ & $1.68 \pm 0.05$ & $1.35 \pm 0.035$ \\
1600 & $0.25 \pm 0.025$ & $0.30 \pm 0.02$ & $0.99 \pm 0.05$ & $0.72 \pm 0.025$ \\
2200 & $0.13 \pm 0.02$ & $0.165 \pm 0.015$ & $0.57 \pm 0.035$ & $0.41 \pm 0.015$ \\
\hline
\end{tabular}

is about $51^{\circ}\left( \pm 2^{\circ}\right)$ for both days and all observations are performed at nadir. The scattering angle is close to $130^{\circ}$. The average altitude of the aircraft was 11.5 and $10 \mathrm{~km}$ on 11 and 8 October, respectively.

[23] The total and polarized reflectances increase as the wavelength decreases due to the impact of molecular scattering, as expected. In the worst conditions the signal-to-noise ratio is about 10 in polarized reflectance and 30 in total reflectance. It gives a high level of confidence into the measurements performed by this new instrument. After subtracting in each band the molecular component and the surface contribution (estimated using the Cox and Munk [1954] model), we have plotted the total and polarized reflectances, normalized at $865 \mathrm{~nm}$, as a function of the wavelength, in Figures 6a and $6 \mathrm{~b}$, respectively. The $490 \mathrm{~nm}$ channel in total radiance is not used in the aerosol retrieval scheme and not shown in Figure $6 \mathrm{a}$ because of the uncertainty in the estimation of water leaving radiance. The spectral behavior, in total reflectance, related to mineral dust case and maritime aerosol is quite similar. This result suggests that retrieved size parameters for both days should be comparable. However, a difference in the slope value can be observed between the two transects sampled for maritime aerosols study. The polarized spectral dependence displayed on Figure $6 \mathrm{~b}$ is significantly more pronounced for oceanic aerosols and confirms that polarization can offer a powerful tool for remote sensing of aerosol type.

[24] We first present the MICROPOL retrievals obtained for the "R solution" where the results presented hereafter are averaged over $5 \mathrm{~s}$. Figures $7 \mathrm{a}$ and $7 \mathrm{~b}$ show the aerosol optical thickness at $865 \mathrm{~nm}$ and the effective radius retrieved from MICROPOL observations for the dusty day of 11 October. Missing parts correspond to cloudy structures detected on the lidar cross section (Figures $1 \mathrm{~b}$ and $1 \mathrm{c}$ ). The gradient in the MODIS AOT (Figure 1a) is also observed in the MICROPOL retrieved AOT on Figure 7a. The AOT decreases from 0.23 to 0.11 between the French coast and the Corsica Island. The Sun photometer posted on the French seashore (located at $3^{\circ} 53^{\prime} \mathrm{E}, 43^{\circ} 36^{\prime} \mathrm{N}$; see Figure 1a)

Table 4b. Mean Polarized Reflectances Expressed in Percent and Standard Deviations for the Corresponding Transect ${ }^{\mathrm{a}}$

\begin{tabular}{ccccc}
\hline Band, nm & Zone 1 & Zone 2 & Zone 3 & Zone 4 \\
\hline 490 & $1.47 \pm 0.04$ & $1.52 \pm 0.025$ & $1.6 \pm 0.05$ & $1.46 \pm 0.05$ \\
670 & $0.515 \pm 0.015$ & $0.53 \pm 0.01$ & $0.64 \pm 0.025$ & $0.57 \pm 0.02$ \\
865 & $0.245 \pm 0.01$ & $0.26 \pm 0.01$ & $0.40 \pm 0.02$ & $0.32 \pm 0.01$ \\
1600 & $0.07 \pm 0.01$ & $0.085 \pm 0.01$ & $0.26 \pm 0.02$ & $0.18 \pm 0.01$ \\
2200 & $0.04 \pm 0.005$ & $0.05 \pm 0.005$ & $0.165 \pm 0.01$ & $0.115 \pm 0.01$ \\
\hline
\end{tabular}

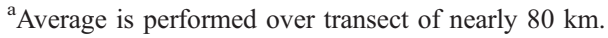

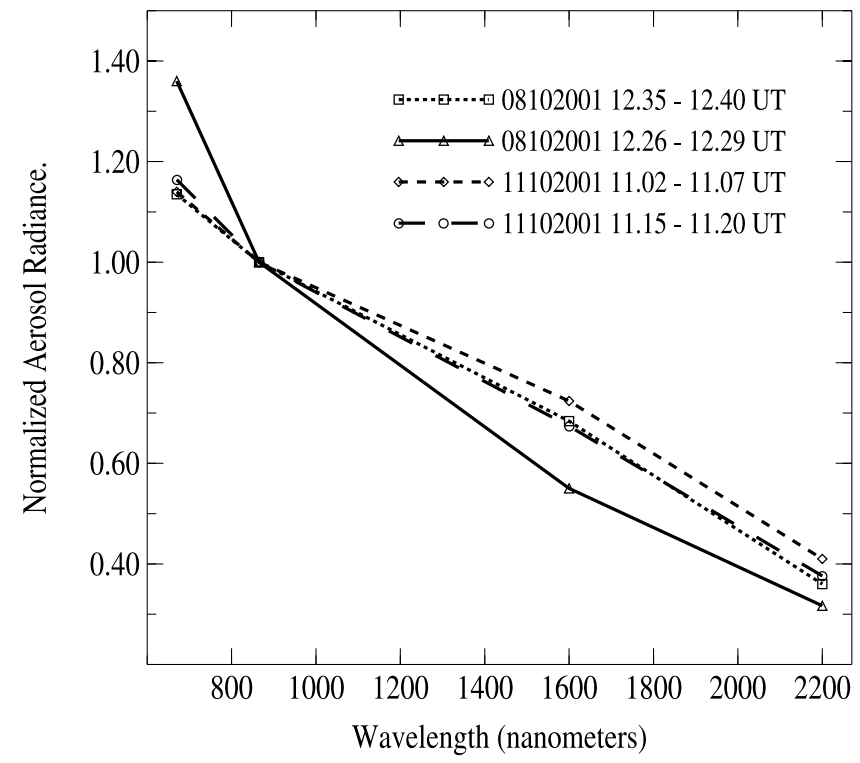

(a)

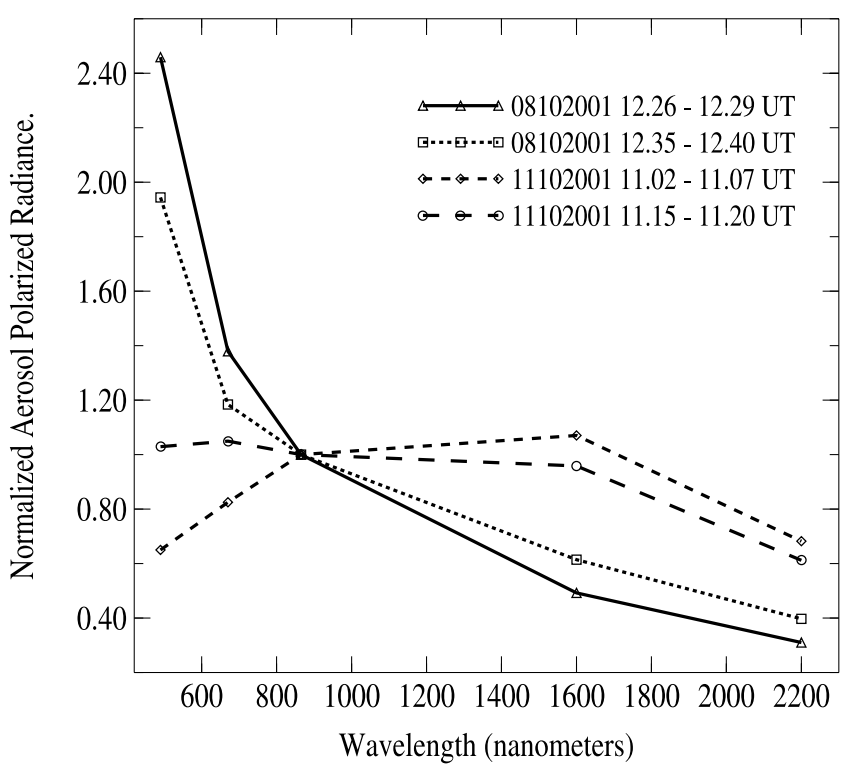

(b)

Figure 6. (a) Normalized aerosol radiance and (b) normalized aerosol polarized radiance in function of wavelength.

indicates an average AOT of $0.18 \pm 0.05$ between 0900 and $1000 \mathrm{UT}$, which is in an excellent agreement with the MICROPOL AOT. Figure $7 \mathrm{~b}$ shows that the effective radius remains rather constant. The average value derived along the transect, after rejection of cloud areas, is equal to $0.43 \mu \mathrm{m}$. Small fluctuations of less than $0.06 \mu \mathrm{m}$ are observed. The retrieved Angström parameter (not shown), computed over the 865 and $670 \mathrm{~nm}$ [Deuzé et al., 2000], is close to $0.6 \pm 0.2$, while the Sun photometer at the seashore indicates a value of 0.2 . This discrepancy can be explained by the fact that the Angström parameter is very sensitive to the relative contribution of mineral dust to the total optical thickness, especially when the Angström exponent is between 1.0 and 0.2 [Hamonou et al., 1999]. As the observations were performed on the edge of the dust plume, we can 


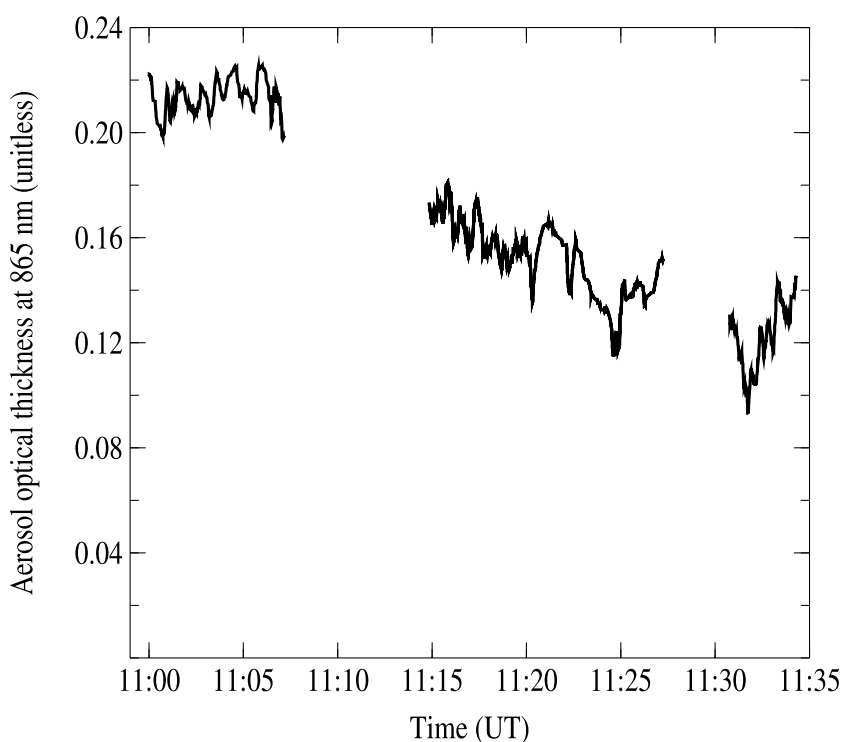

(a)

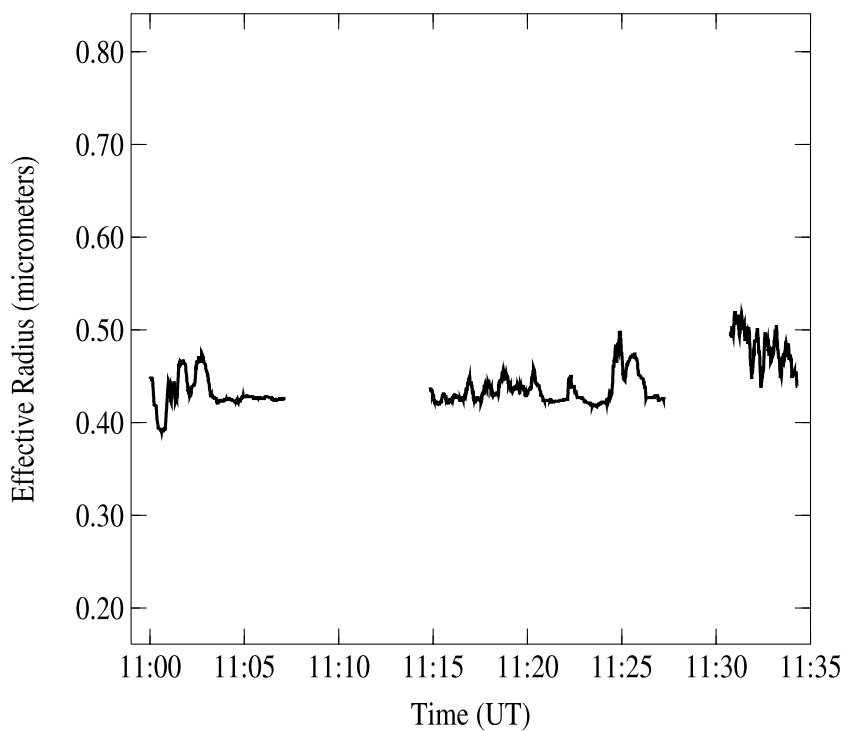

(b)

Figure 7. (a) Aerosol optical thickness at $865 \mathrm{~nm}$ and (b) effective radii in micrometers retrieved by MICROPOL on 11 October 2001.

expect a strong variability in the relative contribution of the dust as it is shown by the measurements in Avignon. Indeed, the Angström exponent measured in Avignon shows a decrease from 1 to 0.2 during the day as the dust layer moves northward. The small mode concentration ( $\eta$, not shown) varies from 35 to $50 \%$. This suggests that large particles are rather predominant in the aerosol size distribution. The best fit in radiance is obtained for a mixture of models 4 and 5 (see Table 3). The model 6 also represents a possible solution but for less than $10 \%$ of the points. Corresponding residual errors for radiance as well as for polarization $\left(\varepsilon_{\mathrm{R}}\right.$ and $\left.\varepsilon_{\mathrm{RP}}\right)$ are equal to $2.8 \%$ and $5 \%$, respectively. The aerosol parameters derived using the "R + P" or the " $R$ " solutions are exactly the same. This confirms that the models chosen by the algorithm are also suitable to represent the polarization induced by the aero- sols. This result tends to indicate that most of the particles in the air are spherical since the retrieved models 4 and 5 are spherical. The small aerosol particles have the property to generate more polarization than the larger spherical and nonspherical particles. If the major part of the particles observed in the dust plume were nonspherical, the polarized radiance generated by such particles would have been very low. This is not the case here because the solution chosen by the algorithm, which is a mixed of about $50 \%$ of small and large particles, is suitable to represent the polarization generated by the observed aerosols. This result confirms that the contribution of the small mode to the aerosol size distribution is as important as the contribution of the large mode. However, we cannot conclude that the mineral particles observed here follow a bimodal size distribution as we cannot neglect the possibility of a mixing with anthropogenic particles in the atmosphere.

[25] Figures $8 \mathrm{a}$ and $8 \mathrm{~b}$ show the aerosol optical thickness at $865 \mathrm{~nm}$ and the effective radius retrieved by MICROPOL on 8 October. The missing parts in the plot correspond to small clouds detected by the lidar. Over the marine boundary layer where clouds have been identified by lidar (Figures $2 \mathrm{~b}$ and $2 \mathrm{c}$ ), the residual error goes over the $5 \%$ threshold $(10 \%-15 \%)$. The AOT retrieved over the maritime aerosol layer is between 0.04 and 0.12 . Effective radii decrease slightly from 0.42 to $0.36 \mu \mathrm{m}$ between 1233 and 1245 UT. This corresponds to an increase of the Angström parameter from 0.6 to 1.1 . The residual fitting error in radiance is ranging from $2 \%$ to $1 \%$ from the beginning to the end of the transect. The corresponding fit in polarization, $\varepsilon_{\mathrm{RP}}$, is about $8 \%$. A mixture of about $50 \%$ of model 4 (see Table 3) and $50 \%$ of model 5 is found. The increase in the effective radius observed between 1230 and 1233 UT is associated to small values of $\eta$ (down to 0.3 ) in association with the previous models. In agreement with the more pronounced spectral dependence observed in Figure 6a, the retrieved effective radius between 1215 and 1218 UT and between 1226 and 1229 UT are smaller. The effective radius ranges from 0.18 to $0.32 \mu \mathrm{m}$ and the Angström parameter is close to 1.2. A combination of models 2 or 3 associated with model 7 is retrieved with a relative concentration of about $70-75 \%$. The " $\mathrm{R}+\mathrm{P}$ " approach leads to the same optical thickness (difference less than 0.005), but the set of models and the effective radius are different for the region over-passed between 1233 and 1245 UT (Figure $8 \mathrm{~b}$ ). The decrease in effective radius along the transect is more pronounced than for the " $\mathrm{R}$ solution." This decrease is due to a change in the retrieved models rather than in a change in the contribution of the small mode to the total optical thickness. A combination of models 4 and 7 is retrieved in the region between 1233 and 0240 UT, whereas models 3 and 6 are retrieved between 1240 and 1245 UT. The retrieved concentration $(\eta)$ is more stable than for the "R solution" over the transect of interest and remains close to 0.7 . For these regions the residual error in polarization decreases to $6 \%$, whereas the residual error in radiance is between 2.5 and $1.5 \%$.

\subsection{Comparison With MODIS Retrievals}

[26] The TERRA/MODIS has performed observations over the same area at around 1030 UT on 11 October and at around 1000 UT on 8 October. The airborne measure- 


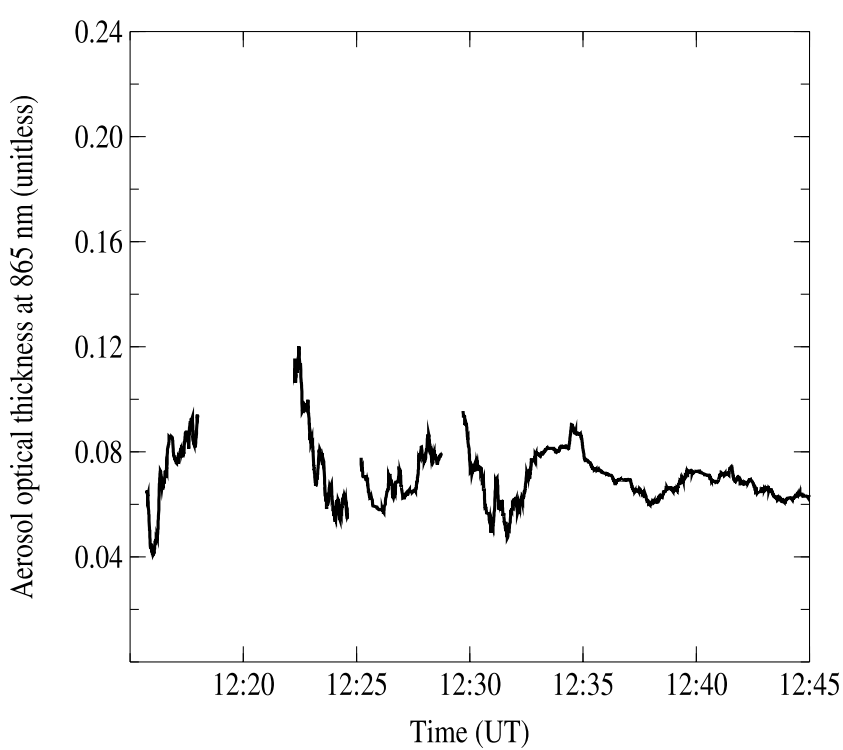

(a)

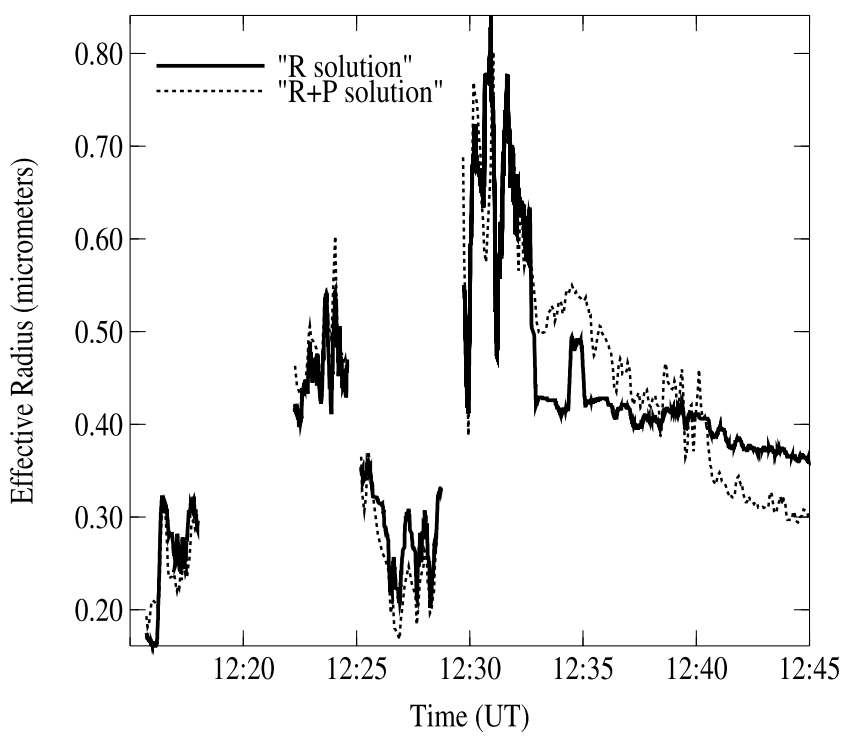

(b)

Figure 8. (a) Aerosol optical thickness at $865 \mathrm{~nm}$ and (b) effective radii in micrometers retrieved by MICROPOL on 8 October 2001.

ments were performed within $30 \mathrm{~min}$ after the satellite overpass on 11 October and more than 2 hours later on 8 October. The MODIS aerosol products are given at $10 \mathrm{~km} \times$ $10 \mathrm{~km}$ resolution, while the size spot of MICROPOL is nearly $400 \mathrm{~m}$ depending on the aircraft altitude. In order to compare both retrievals, all the MICROPOL pixels located within the MODIS superpixel are selected to average the aerosol parameters. A superpixel corresponds to about $10 \times$ 10 elementary MODIS pixels. The selection criteria is that the distance between the center of the MODIS pixel, and the MICROPOL pixel has to remain lower than $6 \mathrm{~km}$. Figure 9 shows the comparison of the retrieved MICROPOL AOT ("R solution") versus the MODIS one for the two considered days. The error bars on the MICROPOL AOT represent the variability within each MODIS pixel. The agreement be- tween the two sensors is excellent. We have also compared the effective radius, asymmetry parameter at $865 \mathrm{~nm}$, the Angström parameter computed over 670 and $865 \mathrm{~nm}$, and the small mode concentration at $865 \mathrm{~nm}$. We consider both the best solution, corresponding to the smallest residual fitting error, and the average MODIS solution [Tanré et al., 1997; Remer et al., 2002]. The comparison is reported in Table 5. We have also reported the numbers of the large and small aerosol models retrieved for the best solution, the residual error, and finally the scattering angle.

[27] On 11 October we can see a very good agreement in the effective radii retrieved by MODIS (best solution) and MICROPOL, equal to 0.48 and $0.45 \mu \mathrm{m}$, respectively. The MICROPOL retrieved asymmetry parameter is also in a good agreement with the MODIS one when considering the MODIS absolute accuracy $( \pm 0.03)$ for this parameter. There is a noticeable difference between the MODIS best and average solutions of the effective radius when the small mode concentration and the Angström exponent, for the average solution, compare much better to MICROPOL. The size of the small and the large modes is different in the MICROPOL and MODIS retrievals (see Table 5) as well as the contribution of the small mode to the optical thickness. However, the derived AOT and effective radii are similar. It indicates that the inversion is sensitive to the total optical thickness and the effective radius of the total size distribution, not to the size of the small and the large models.

[28] On 8 October large fluctuations can be observed in the retrieved size parameters: the average values of effective radius retrieved by MODIS for the best and the average solutions are twice as much as MICROPOL best solution. Depending on the part of transect, as already shown on Figure $8 b$, the MICROPOL effective radius exhibits a high variability, ranging from 0.2 to $0.8 \mu \mathrm{m}$, leading to an average value of $0.40 \mu \mathrm{m}$. The predomination of the coarse mode on the aerosol size distribution is clearly shown by both instruments. The contribution of the small mode to the total AOT is about the same in both retrievals. However, the

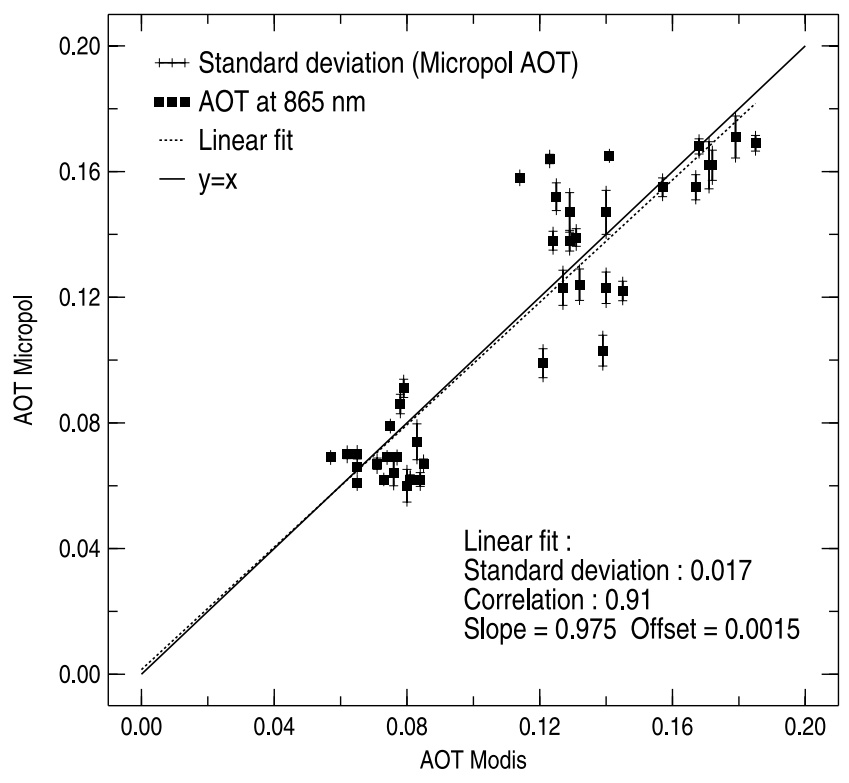

Figure 9. Comparison between the AOT retrieved by MODIS and MICROPOL at $865 \mathrm{~nm}$. 
Table 5. Comparison Between MICROPOL and MODIS Retrievals (Radiance Only Inversion) ${ }^{\mathrm{a}}$

\begin{tabular}{|c|c|c|c|c|c|c|}
\hline \multirow[b]{2}{*}{ Type of Solution } & \multicolumn{3}{|c|}{11 October 2001} & \multicolumn{3}{|c|}{8 October 2001} \\
\hline & MICROPOL & MODIS Best & MODIS Average & MICROPOL & MODIS Best & MODIS Average \\
\hline Effective radius & $0.45 \pm 0.004$ & $0.48 \pm 0.003$ & $0.65 \pm 0.04$ & $0.40 \pm 0.09$ & $0.80 \pm 0.07$ & $0.79 \pm 0.05$ \\
\hline Asymmetry parameter & $0.71 \pm 0.0015$ & $0.69 \pm 0.007$ & $0.70 \pm 0.01$ & $0.69 \pm 0.03$ & $0.72 \pm 0.006$ & $0.715 \pm 0.003$ \\
\hline Small mode concentration & $0.43 \pm 0.05$ & $0.36 \pm 0.07$ & $0.49 \pm 0.05$ & $0.57 \pm 0.13$ & $0.53 \pm 0.05$ & $0.52 \pm 0.05$ \\
\hline Angström exponent & $0.69 \pm 0.05$ & $0.42 \pm 0.10$ & $0.60 \pm 0.10$ & $0.6-1.2$ & $0.65 \pm 0.09$ & $0.63 \pm 0.10$ \\
\hline Small model number & 4 & 1 & - & 4 & 3 or 4 & - \\
\hline Large model number & 5 & 6 & - & 5 & 7 & - \\
\hline Residual fitting error & $\approx 3 \%$ & $2-4 \%$ & & $1-2 \%$ & $3.5-6.5 \%$ & \\
\hline Scattering angle & $\approx 126^{\circ}$ & $139^{\circ}-130^{\circ}$ & & $\approx 126^{\circ}$ & $139^{\circ}-130^{\circ}$ & \\
\hline
\end{tabular}

${ }^{\mathrm{a}}$ The retrieved parameters are averaged on the respective aircraft leg displayed on Figures $1 \mathrm{~b}$ and $2 \mathrm{~b}$. The variability of the retrieved parameter is reported in the table as a standard deviation (over the leg). Minimum and maximum residual fitting errors and scattering angles are also given.

retrieved coarse mode is different, leading to this difference in the effective radius as well as in the asymmetry parameter. MODIS residual fitting errors are slightly higher than on 11 October, ranging from 3.5 to $6.5 \%$, and significantly higher than for MICROPOL.

\subsection{Properties of the Vertical Structure}

[29] The vertical distribution of aerosol extinction in the atmosphere results from production, sedimentation, accumulation, and mixing processes. The vertical profile of the clean marine boundary aerosol average concentration can be approximated by an exponential decay with the altitude. As sulfate and sea salt are hygroscopic, their radius, refractive index, and extinction properties will be affected by the relative humidity. Comparatively, one or several lofted layers in the free troposphere usually characterize dust transport [Hamonou et al., 1999, Léon et al., 2003]. A complex multilayer structure can reveal the contribution of different sources to the same plume, resulting in a difference in the dust size and optical properties. Pure dust particles are usually assumed to be nonhygroscopic. Moreover, owing to its desert origin, dust is transported in a dry air mass, thus minimizing humidity effects. However, the uptake of sulfate as a shell by the dust may modify their hygroscopic properties [Levin et al., 1996]. On 8 October, most of the aerosol signal comes from the marine boundary layer, while in the second case dust is observed up to $5 \mathrm{~km}$ high. The objective is here to derive from the lidar signal some information on the vertical distribution of aerosol properties by using MICROPOL retrievals.

[30] Retrieving the extinction coefficient from nadir elastic backscatter lidar measurements requires the knowledge of the backscatter-to-extinction ratio, which depends on the particle type. The color ratio is not sufficient to constrain the restitution of the extinction profile from the lidar signal. The lidar inversion can be constrained by using columnar aerosol properties derived from passive radiometer measuring the top-of-the-atmosphere radiances. We have applied here a method proposed by Léon et al. [2003], which makes use of the total optical thickness and the effective radius retrieved by the MODIS to constrain the lidar inversion. As the two instruments are on the same airplane, the measurements are simultaneous in space and time. The aircraft is equipped with standard broadband radiometers to measure the upward and downward solar fluxes and to ensure clear conditions above the aircraft. During the measurements, there is no cloud or aerosol above the aircraft. The method relies on the use of the color ratio to determine the contribution of the small mode of particles to the total aerosol extinction as a function of the altitude. The procedure does not allow retrieving the vertical profile of the size of the coarse mode and small mode independently, and we have to assume that the characteristics of each mode of particle do not change with altitude. Only the relative contribution of each mode can vary. In this case, there is a one-to-one relationship between the ratio of the backscatter coefficient between 532 and $1064 \mathrm{~nm}$ and the ratio of the small to the total extinction [Léon et al., 2003]. The retrieval scheme is an iterative procedure starting from the bottom of the atmosphere. The procedure follows: (1) evaluation of the atmospheric transmission using the aerosol optical thickness (in the first step the optical thickness derived from MICROPOL is used), (2) estimation of the relative contribution of the small mode to the total extinction from the ratio of the lidar backscatter coefficients corrected from the atmospheric transmission, (3) estimation of the backscatter-to-extinction ratio, and (4) estimation of the aerosol extinction coefficient. The 20 retrieved profiles of extinction and effective radius are vertically integrated and compared to the solutions retrieved by the passive sensor. We retain only the set of profiles for which both the columnar integrated aerosol optical thickness and the effective radius fall within the accuracy of the retrieval of this parameter by MICROPOL. The error in the retrieval due to signal detection and calibration of the lidar are discussed in the work of Léon et al. [2003]. For a relative calibration and signal detection error of $10 \%$ the vertical profile of aerosol extinction is retrieved within $20 \%$.

[31] Figures 10 and 11 present the retrieved profiles of extinction and effective radius on 8 and 11 October. Figures 10 and 11 correspond to the average of lidar measurements performed between 1115 and 1120 UT on 11 October and between 1235 and 1240 UT on 8 October. The average extinction within the dust layer is about $0.05-$ $0.12 \mathrm{~km}^{-1}$. Aerosols are detected up to 3 and $6 \mathrm{~km}$ high in the maritime and dust profiles. The inversion procedure can give an estimate of the effective radius of the particles as a function of the altitude. Within the dust layer the effective radius is quasi-constant as a function of the altitude and equal to $0.35 \mu \mathrm{m}$. In the profile derived on 8 October the effective radius increases at the top of the marine boundary layer, which is assumed to correspond to the condensation of water onto particles as seen from the PCR decrease.

\section{Discussion and Conclusion}

[32] Airborne lidar and passive radiometer have been used to investigate the two-dimensional structure and the 


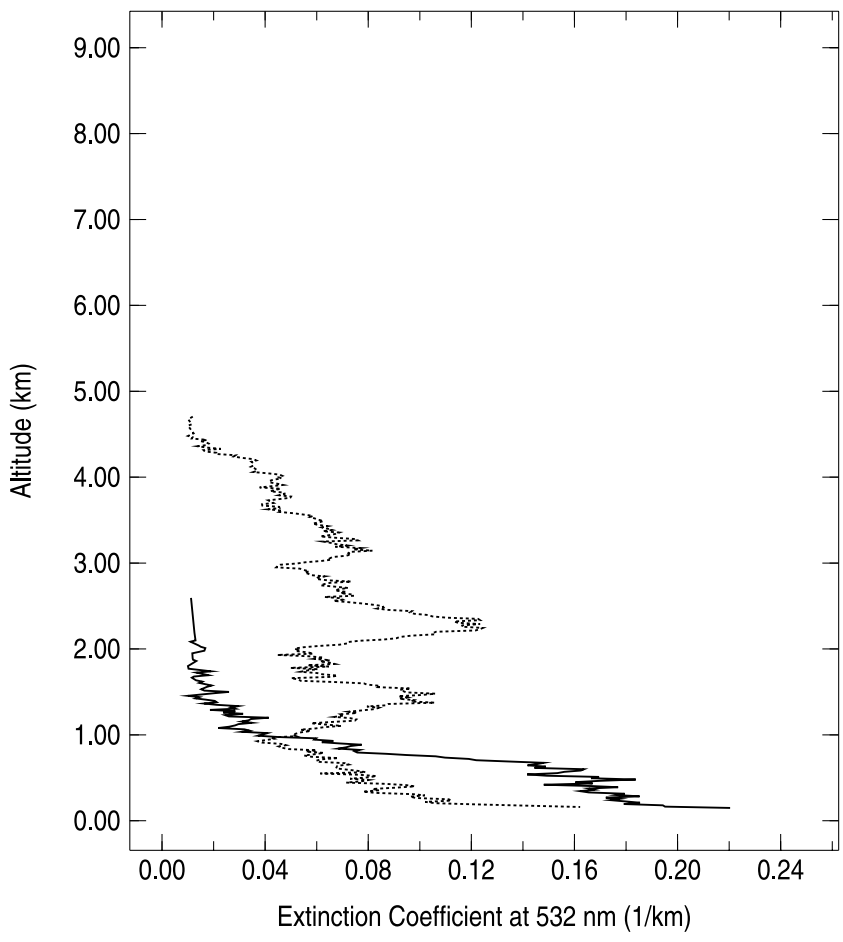

Figure 10. Extinction coefficient at $532 \mathrm{~nm}$ on (dashed line) 11 October and (solid line) 8 October.

optical properties of a Saharan dust layer as well as a maritime aerosol layer over the Mediterranean Sea. The vertical structure of the dust plume exhibits a high uniformity in the effective radius value, which is nearly constant and close to $0.35 \mu \mathrm{m}$. We can also observe that the effective radius and the asymmetry parameter, derived from the aerosol models retrieved by MICROPOL, display small standard deviations over $500 \mathrm{~km}$ (French coast to Corsica Island), which indicates that the optical and physical properties associated to the dust layer are also rather constant horizontally. Indeed, the dust is expected to come from southern Algeria. However, we have not sampled the core of the dust event but only the edge of the plume. The analysis of the depolarization ratios confirms the presence of nonspherical particles in the dust layer. However, the depolarization coefficient was surprisingly low, about $4 \%$, as compared to a previous study of the same plume. Indeed, Müller et al. [2003] have observed a depolarization coefficient varying from 10 to $25 \%$ during the overpass of the plume over Leipzig (Germany), between 13 and 14 October. It clearly indicates that the depolarization ratio may be a nonuniform parameter within a dust plume. The altitude of the top of the dust layer is $6 \mathrm{~km}$ and stays rather constant as the plume moves northward [Müller et al., 2003]. The effective radius inferred from the synergy between the lidar and the MICROPOL is constant with the altitude, which confirms that we have observed a rather aged plume, where the largest particles have already been removed by sedimentation.

[33] The main observed difference between mineral dust and maritime aerosol as observed by a remote sensor is the optical thickness. Indeed, on 8 October, for the maritime observation, AOT is close to 0.1 , whereas it is 0.3 in the case of the Saharan dust. In the maritime case the vertical distribution revealed by the lidar shows that most of the aerosol extinction is confined in the marine boundary layer below $1 \mathrm{~km}$. However, large particles are observed in the transition layer up to $2 \mathrm{~km}$. An increase in effective radius from 0.2 to $0.3 \mu \mathrm{m}$ is observed between the $150 \mathrm{~m}$ and the upper part of the boundary marine layer. A high horizontally variability in the retrieved maritime aerosols parameters is also observed. As the observation is here performed over the emission area, it is expected to have only small-scale variability in the aerosol extinction due to local scale variation in the surface wind speed. As expected in the case of maritime particles (which are expected to be spherical), no significant depolarization was observed within the marine boundary layer.

[34] A comparison between MODIS and MICROPOL instruments has been performed. The inversion schemes are similar, except that MODIS uses six wavelengths ranging from 550 to $2135 \mathrm{~nm}$ against four for MICROPOL ranging from 670 to $2200 \mathrm{~nm}$. The comparison of the aerosols products retrieved by MICROPOL and MODIS during the dust outbreak is very encouraging. The derived AOT and effective radius are consistent. On 8 October the comparison between MODIS and MICROPOL is more questionable. The AOT is significantly lower than on 11 October. The ability of the MODIS inversion to retrieve any information about the aerosol size distribution is directly related to the aerosol loading. At higher optical thickness the contribution of the aerosols to the signal is more important and the retrievals are generally more reliable [Remer et al., 2002]. The low loading conditions observed here on 8 October and the high variability in the retrieved parameters are probably a source of uncertainty in the MODIS and MICROPOL retrievals and intercomparison. The difference in the in acquisition time (up to 2 hours), and

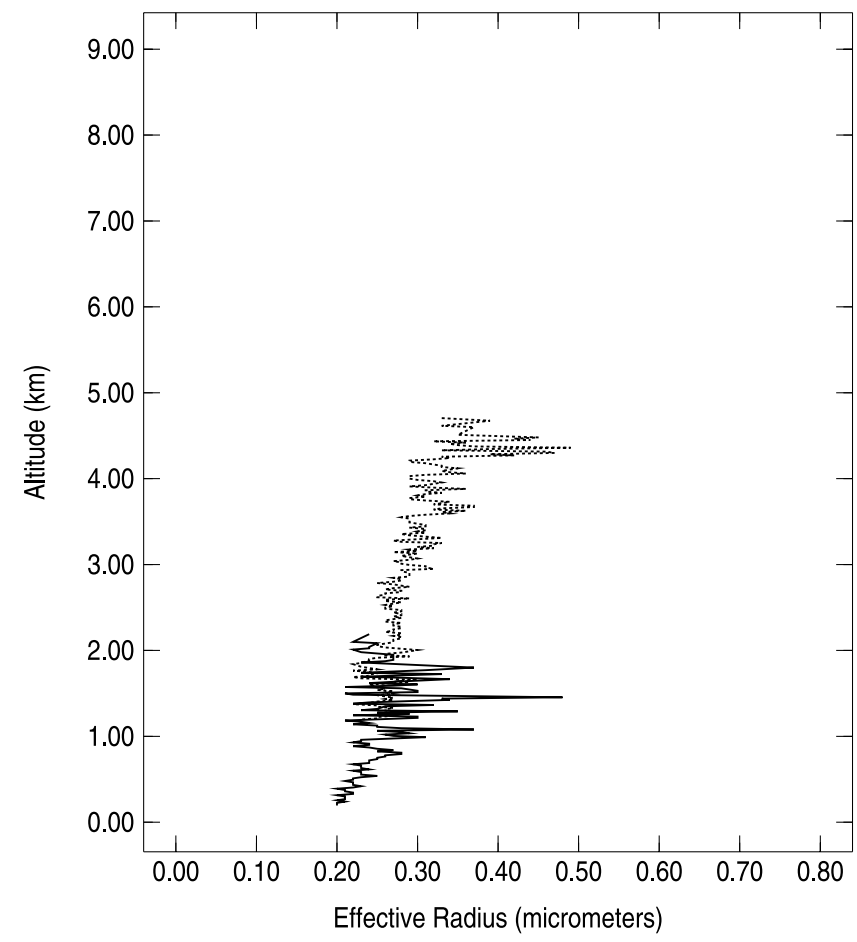

Figure 11. Vertical profiles of effective radius on (dashed line) 11 October and (solid line) 8 October. 
potential contamination of clouds, constitutes some other probable sources of errors in the comparison.

[35] The spectral polarized measurements acquired by MICROPOL have revealed a large disparity in the wavelength dependence of the polarized radiances generated by both types of aerosols. However, the polarized radiances generated by maritime and mineral dust aerosols are well simulated by our inversion and models. Considering that the nonspherical model represents the coarse mode of particles, the best solution on 11 October corresponds to a mixture of $50 \%$ of nonspherical model and water-soluble with humidity model (model 4 ; see Table 3 ). The optimal $\varepsilon_{R}$ and $\varepsilon_{R P}$ are $3.5 \%$ and $11 \%$, respectively. It indicates that the proposed nonspherical model is not able to reproduce the scattering properties of the observed aerosols for the given geometry. This result is consistent with the weak observed lidar depolarization ratio. However, we need more observations on the mineral dust physical properties to generalize this finding and to understand the natural variability of the shape of the particles in the atmosphere.

[36] Acknowledgments. The authors would like to acknowledge the technical staff of laboratoire d'optique atmospherique, namely J. Balois, C. Verwaerde and F. Auriol. The authors are grateful to the 2 pilots of the aircraft and to the technical staff of Institut National des Sciences de l'Univers (INSU) for their support on the aircraft and lidar. The authors are also grateful to F. Lavenu and M. Verbrugghe for providing ground-based measurements during the experiment. The development of the MICROPOL polarimeter is funded by the Centre national d'Etudes Spatiales (CNES) and the Conseil regional du Nord-pas de Calais.

\section{References}

Blanchard, D. C., and A. H. Woodcock (1980), The production, concentration and vertical distribution of the sea-salt aerosol, Ann. N. Y. Acad. Sci. 338, 330-347.

Brogniez, G., F. Parol, L. Bécu, J. Pelon, O. Jourdan, J.-F. Gayet, F. Auriol, C. Verwaerde, J. B. Balois, and B. Damiri (2004), Determination of cirrus radiative parameters from synergy between active and passive remote sensing measurements during the FRENCH/DIRAC 2001: First results and comparison with in situ probes. Preparation to AQUA TRAIN experiment, J. Atmos. Sci., 72, 425-452, doi:10.1016/ j.atmosres.2004.03.026.

Chami, M., R. Santer, and E. Dilligeard (2001), Radiative transfer model for the computation of radiance and polarization for the ocean-atmosphere system: Polarized properties of suspended matter for remote sensing, Appl. Opt., 40, 2398-2416.

Cox, C., and W. Munk (1954), Statistic of the sea surface derived from Sun glitter, J. Mar. Res., 13, 199-227.

Deschamps, P. Y., F. M. Bréon, M. Leroy, A. Podaire, A. Bricaud, J. C. Buriez, and G. Sèze (1994), The POLDER mission: Instrument characteristics and scientific objectives, IEEE Trans. Geosci. Remote Sens., 32, $598-615$

Deuzé, J.-L., M. Herman, and R. Santer (1988), Fourier series expansion of the transfer equation in the atmosphere-ocean system, J. Quant. Spectros. Radiat. Transfer, 41, 483-494.

Deuzé, J.-L., C. Devaux, and M. Herman (1993), Analysis of the POLDER (Polarization and Directionality of Earth Reflectances) airborne instrument observations over land surfaces, Remote Sens. Environ., 45, $137-$ 154.

Deuzé, J. L., et al. (2000), Estimate of the aerosol properties over the ocean with POLDER, J. Geophys. Res., 105, 15,329-15,346.

Dubovik, O., and M. D. King (2000), A flexible inversion algorithm for retrieval of aerosol optical properties from Sun and sky radiance measurements, J. Geophys. Res., 105, 20,673-20,696.

Flamant, C., V. Trouillet, P. Chazette, and J. Pelon (1998), Wind speed dependence of atmospheric boundary layer optical properties and ocean surface reflectance as observed by airborne backscatter LIDAR, J. Geophys. Res., 103, 25,137-25,158.

Goloub, P., F. Waquet, J. L. Deuzé, M. Herman, F. Auriol, J. F. Léon, J. Y. Balois, C. Verwaerde, and D. Tanré (2003), Development of a multispectral polarimeter dedicated to aerosol characterization: Preliminary results, paper presented at 2003 IEEE International Geoscience and
Remote Sensing Symposium 21-25 July 2003, Cent. de Cong. Pierre Baudis, Toulouse.

Hamonou, E., P. Chazette, A. Papayanis, D. Balis, F. Marenco, V. Santacesaria, and G. Ancellet (1999), Characterization of the vertical structure of Saharan dust export to the Mediterranean basin, J. Geophys. Res., 104, 22,257-22,270.

Herman, M., J.-L. Deuzé, C. Devaux, P. Goloub, F.-M. Bréon, and D. Tanré (1997a), Remote sensing of aerosols over land surfaces including polarization measurements and applications to POLDER measurements, J. Geophys. Res., 102, 17,039-17,049.

Herman, J. R., P. K. Barthia, O. Torres, C. Hsu, C. Seftor, and E. Celarier (1997b), Global distribution of UV-absorbing aerosols from Nimbus7/ TOMS data, J. Geophys. Res., 102, 16,911-16,922.

Holben, N. B., et al. (1998), AERONET-A federated instrument network and data archive for aerosol characterisation, Remote Sens. Environ., 66, $1-16$.

Kaufman, Y. J., D. Tanré, and O. Boucher (2002), A satellite view of aerosols in the climate system, Nature, 419, 215-223, doi:10/1038/ nature01091.

Kaufman, Y. J., D. Tanré, J.-F. Léon, and J. Pelon (2003a), Retrieval of profiles of fine and coarse aerosols using lidar and radiometric space measurements, IEEE Trans. Geosci. Remote Sens., 41, 1743-1754.

Kaufman, Y. J., J. M. Haywood, P. V. Hobbs, W. Hart, R. Kleidman, and B. Schmid (2003b), Remote sensing of vertical distributions of smoke aerosol off the coast of Africa, Geophys. Res. Lett., 30(16), 1831, doi:10.1029/2003GL017068.

Léon, J.-F., P. Chazette, and F. Dulac (1999), Retrieval and monitoring of aerosol optical thickness over an urban area by spaceborne and groundbased remote sensing, Appl. Opt., 38, 6918-6926.

Léon, J., D. Tanré, J. Pelon, Y. J. Kaufman, J. M. Haywood, and B. Chatenet (2003), Profiling of a Saharan dust outbreak based on a synergy between active and passive remote sensing, J. Geophys. Res., 108(D18), 8575, doi: $10.1029 / 2002 J D 002774$

Leroy, M., J. L. Deuzé, F. M. Bréon, O. Hautecoeur, M. Herman, J. C. Buriez, D. Tanré, S. Bouffies, P. Chazette, and J. L. Roujean (1997), Retrieval of atmospheric properties and surface bi-directional reflectances over land from POLDER/ADEOS, J. Geophys. Res., 102, 17,023$17,037$.

Levin, Z., E. Ganor, and E. Gladstein (1996), The effect of desert particles coated with sulfate on rain formation in the eastern Mediterranean, J. Appl. Meteorol., 35, 1511-1523.

Müller, D., U. Wandinger, and A. Ansmann (1999a), Microphysical particle parameters from extinction and backscatter LIDAR data by inversion with regularization: Theory, Appl. Opt., 38, 2346-2357.

Müller, D., U. Wandinger, and A. Ansmann (1999b), Microphysical particle parameters from extinction and backscatter lidar data by inversion with regularization: Simulation, Appl. Opt., 38, 2358-2368.

Müller, D., I. Mattis, U. Wandinger, A. Ansmann, D. Althausen, O. Dubovik, S. Eckhardt, and A. Stohl (2003), Saharan dust over a central European EARLINET-AERONET site: Combined observations with Raman lidar and Sun photometer, J. Geophys. Res., 108(D12), 4345, doi:10.1029/ 2002JD002918.

Pelon, J., P. H. Flamant, and M. Meisonnier (1990), The French airborne backscatter lidar Leandre-1: Conception and operation, paper presented at 15th International Laser Radar Conference, Int. Coord., Gr. on Laser Atmos. Stud., Tomsk.

Pelon, J., C. Flamant, P. Chazette, J.-F. Leon, D. Tanre, M. Sicard, and S. K. Satheesh (2002), Characterization of aerosol spatial distribution and optical properties over the Indian Ocean from airborne LIDAR and radiometry during INDOEX'99, J. Geophys. Res., 107(D19), 8029, doi:10.1029/2001JD000402.

Prospero, J. M., P. Ginoux, O. Torres, S. E. Nicholson, and T. E. Gill (2002), Environmental characterization of global sources of atmospheric soil dust identified with the NIMBUS 7 Total Ozone Mapping Spectrometer (TOMS) absorbing aerosol product, Rev. Geophys., 40(1), 1002 , doi:10.1029/2000RG000095.

Remer, L. A., et al. (2002), Validation of MODIS aerosol retrieval over ocean, Geophys. Res. Lett., 29(12), 8008, doi:10.1029/2001GL013204.

Salomonson, V. V., W. L. Barnes, P. W. Maymon, H. E. Montgomery, and H. Ostrow (1989), MODIS: Advanced facility instrument for studies of the Earth as a system, IEEE Trans. Geosci. Remote Sens., 27, 145-153.

Sassen, K., and Y. Takano (2000), Parry arc: A polarization lidar, ray tracing, and aircraft case study, Appl. Opt., 39, 6738-6745.

Shettle, E. P., and R. W. Fenn (1979), Models for the aerosols of the lower atmosphere and the effects of humidity variation on their optical properties, AFGL Rep TR-79-0214, Air Force Geophys. Lab., Bedford, Mass.

Sicard, M., P. Chazette, J. Pelon, J. G. Wong, and S.-C. Yoon (2002), Variational method for the retrieval of the optical thickness and the backscatter coefficient from multiangle LIDAR profiles, Appl. Opt., 41, 493502 . 
Tanré, D., Y. J. Kaufman, and S. Matoo (1997), Remote sensing of aerosol properties over oceans using the MODIS/EOS spectral radiances, J. Geophys. Res., 102, 16,971-16,988.

Volten, H., O. Muñoz, E. Rol, J. F. de Haan, W. Vassen, and J. W. Hovenier (2001), Scattering matrices of mineral aerosol particles at $41.6 \mathrm{~nm}$ and $632.8 \mathrm{~nm}$, J. Geophys. Res., Res., 106, 17,375-17,401.

Wang, M., and H. R. Gordon (1994), Radiance reflected from the oceanatmosphere system: Synthesis from individual components of the aerosols size distribution, Appl. Opt., 33, 7088-7095.

Winker, D., J. Pelon, and M. P. McCormick (2002), The CALIPSO mission: Aerosol and cloud observations from space, in 21th International Lidar
Radar Conference, pp. 735-738, Int. Coord. on Laser Atmos. Stud., Québec City, 8-10 July 2002.

J.-L. Deuzé, P. Goloub, J.-F. Léon, D. Tanré, and F. Waquet, Laboratoire d'Optique Atmosphérique, Cité Scientifique, Université de Lille1, F-59655 Villeneuve d'Ascq, France. (leon@loa.univ-lille1.fr)

J. Pelon, Service d'Aéronomie, CNRS, Université Pierre et Marie Curie, F-75252 Paris, France. 